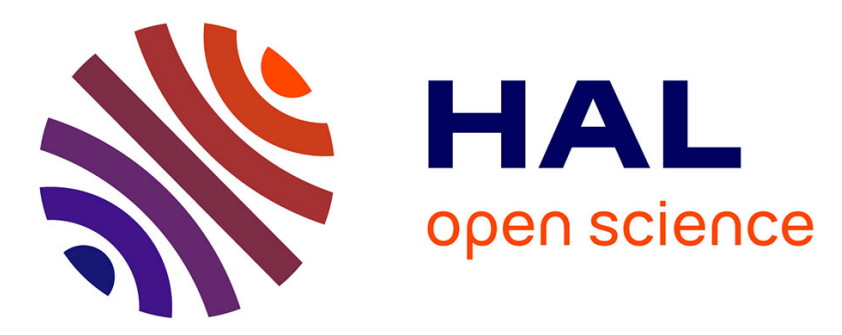

\title{
Advanced numerical modelling of caisson foundations in sand to investigate the failure envelope in the $\mathrm{H}-\mathrm{M}-\mathrm{V}$ space
}

\author{
Zhuang Jin, Zhen-Yu Yin, Panagiotis Kotronis, Zheng Li
}

\section{- To cite this version:}

Zhuang Jin, Zhen-Yu Yin, Panagiotis Kotronis, Zheng Li. Advanced numerical modelling of caisson foundations in sand to investigate the failure envelope in the H-M-V space. Ocean Engineering, 2019, 190, 10.1016/j.oceaneng.2019.106394 . hal-02292422

\section{HAL Id: hal-02292422 \\ https://hal.science/hal-02292422}

Submitted on 21 Oct 2019

HAL is a multi-disciplinary open access archive for the deposit and dissemination of scientific research documents, whether they are published or not. The documents may come from teaching and research institutions in France or abroad, or from public or private research centers.
L'archive ouverte pluridisciplinaire HAL, est destinée au dépôt et à la diffusion de documents scientifiques de niveau recherche, publiés ou non, émanant des établissements d'enseignement et de recherche français ou étrangers, des laboratoires publics ou privés. 


\title{
Advanced numerical modelling of caisson foundations in sand to investigate the failure envelope in the $H-M-V$ space
}

\author{
Zhuang Jin ${ }^{\mathrm{a}, \mathrm{b}}$, Zhen-Yu Yin ${ }^{\mathrm{a}, *}$, Panagiotis Kotronis ${ }^{\mathrm{b}}$, Zheng $\mathrm{Li}^{\mathrm{c}}$ \\ ${ }^{a}$ Department of Civil and Environmental Engineering, The Hong Kong Polytechnic University, Hung Hom, Kowloon, Hong Kong, China \\ ${ }^{\mathrm{b}}$ Ecole Centrale de Nantes, Universite de Nantes, CNRS, Institut de Recherche en Genie Civil et Mecanique (GeM), UMR 6183, 1 rue de la Noe, BP 92101, 44321, \\ Nantes, cedex 3, France \\ ${ }^{\mathrm{c}}$ IFSTTAR, GERS, GMG, Bouguenais, France
}

\begin{abstract}
This paper focuses on the identification of the failure envelope of a caisson foundation in sand using an advanced critical state-based sand model (SIMSAND) and the Combined Lagrangian Smoothed Particle Hydrodynamics Method (CLSPH). The parameters of the SIMSAND constitutive model are first calibrated using triaxial tests on Baskarp sand. In order to validate the combined CLSPH-SIMSAND approach, a cone penetration test, model tests and a field test on a reduced scale caisson foundation are simulated. After full numerical validations with different scales from laboratory to in-situ conditions, a numerical parametrical study is then introduced considering different sand properties (density, friction angle, deformability, crushability) and caisson dimensions (soil-structure contact surface area, diameter-depth ratio) and complex combined loading paths to identify the failure envelope in the horizontal force $(H)$, bending moment $(M)$, vertical force $(V)$ space. The influence of the caisson foundation contact surface area, aspect ratio and soil parameters are considered and quantified. Finally, an analytical formula is proposed for the 3D failure envelope in the $H-M-V$ space.
\end{abstract}

\section{Introduction}

The design of caisson foundations has recently become an important geotechnical challenge. Although caisson foundations have been used in the oil and gas industry for several decades (Tjelta, 1995, 2001), they have been used for Offshore Wind Turbines (OWT) since the early 21st century (Houlsby et al., 2005, 2006; Iskander et al., 2002; Nguyen-Sy and Houlsby, 2005; Senders, 2009; Villalobos et al., 2004, 2009). Providing a skirt, caisson foundations significantly improve the stiffness and the bearing capacity with the additional expense of a (minor) weight increase compared to classical surface foundations (Villalobos et al., 2003). A caisson foundation is lighter than a gravity platform jacket; nevertheless, the horizontal loads and moments are high in comparison to its weight.

For an optimum caisson foundation design in the offshore field it is necessary to consider the couplings between the vertical force $(V)$, the horizontal force $(H)$ and the bending moment $(M)$. Previous research studies on the bearing capacity of caisson foundations in sand mainly focused in in-situ tests (Hogervorst, 1980; Houlsby et al., 2006; Tjelta, 1995), model test (Byrne and Houlsby, 2001; Cassidy et al., 2002; Foglia et al., 2015; Gottardi et al., 1999; Ibsen et al., 2013, 2014) or finite element method simulations (Gerolymos et al., 2015; Liu et al., 2014; Zafeirakos and Gerolymos, 2016; Jin et al., 2018b). The above experimental or numerical results can be used to construct simplified numerical strategies for design purposes, e.g. macroelements (Byrne and Houlsby, 2001; Cassidy et al., 2002; Cremer et al., 2001; Gottardi et al., 1999; Grange et al., 2008; Li et al., 2016; Montrasio and Nova, 1997; Nova and Montrasio, 1991; Salciarini and Tamagnini, 2009). Following the macroelement concept, the entire soil-foundation system is regarded as a single element with a constitutive law expressed in generalised variables following the plasticity or hypoplasticity theory. Compared to a conventional finite element approach, macroelements are simpler, faster and more robust but suitable only for specific foundation - soil configurations.

The definition of the failure surface is of paramount importance in the development a macroelement (Gottardi and Butterfield, 1993; Gourvenec and Barnett, 2011; Gourvenec and Randolph, 2003; Houlsby and Cassidy, 2002; Li et al., 2014) as it introduces the effects of combined loads for different loading levels. An investigation of the failure surface entirely based on model tests induces however important

\footnotetext{
* Corresponding author.,

E-mail address: zhenyu.yin@polyu.edu.hk (Z.-Y. Yin).
} 
Table 1

Basic constitutive equations of the SIMSAND model.

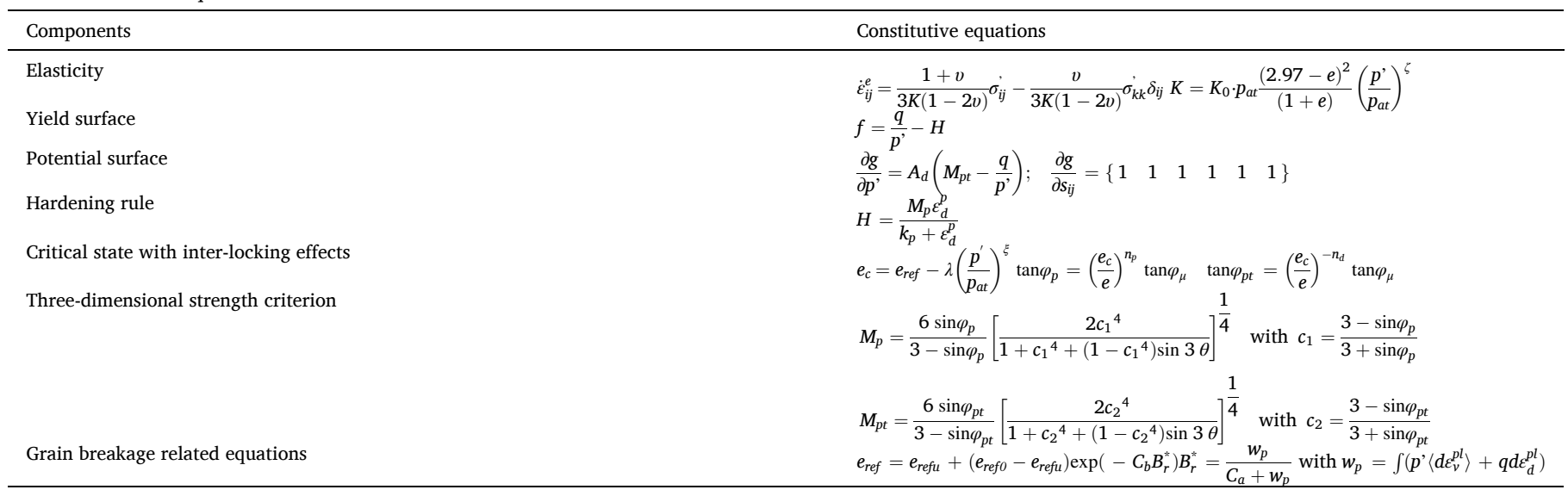

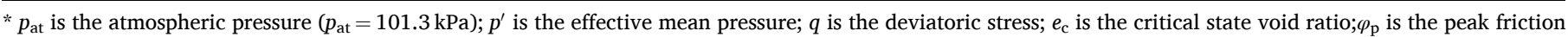

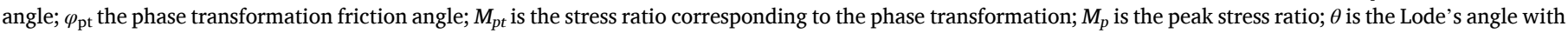

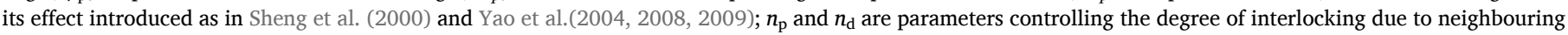

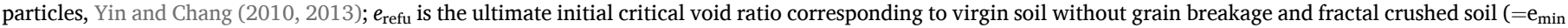

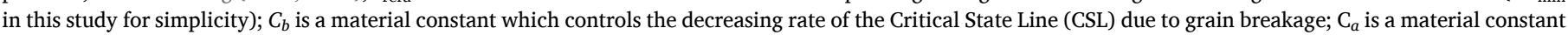
controlling the evolution rate of the modified grain breakage index, Jin et al. (2018a).

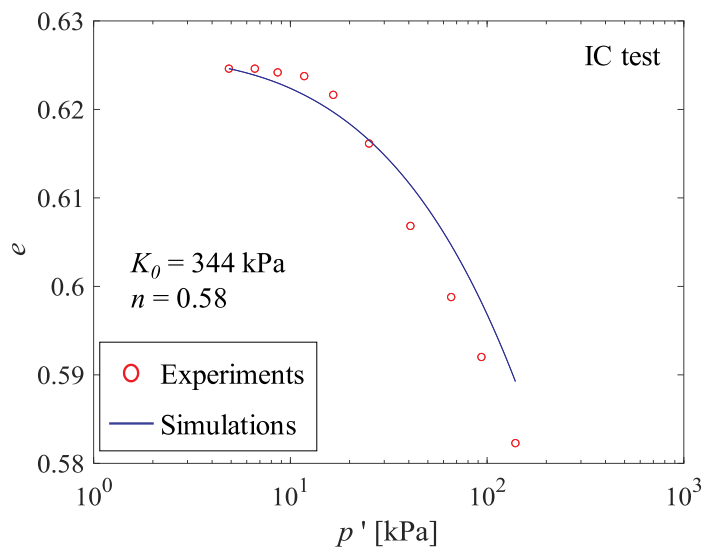

Fig. 1. Calibration of SIMSAND model parameters from isotropic compression test on Baskarp sand.

financial and computational costs (Byrne, 2000; Foglia et al., 2015; Ibsen et al., 2013; Nguyen-Sy, 2005; Villalobos et al., 2010). A timesaving and more economical approach is to use a combination of experiments and finite element method simulations. It is worth noting however that the reliability of the numerical analysis depends on its ability to realistically reproduce the soil nonlinear behaviour.

The response of a caisson foundation in sand subjected to combined loading has been recently simulated with different constitutive models, such as a plasticity constitutive model governed by the Mohr-Coulomb failure criterion (Achmus et al., 2013; Liu et al., 2014; Zafeirakos and Gerolymos, 2016), the NGI - ADP model with an anisotropic undrained shear strength failure criterion (Skau et al., 2018) and an elastoplasticity model called Hardening Small stain Soil model (HSS) which can reproduce basic macroscopic phenomena in the soil (Li et al., 2015). The calibration strategy of the soil parameters is also of great importance. Some studies adopt back calculations from experimental field tests or empirical formulas (Achmus et al., 2013; Zafeirakos and Gerolymos, 2016), the representative soil strength profile of specific areas when the relevant soil parameters are not available (Liu et al., 2014; Skau et al., 2018) or triaxial tests and back analysis using the finite element method (Li et al., 2015). However, the full numerical analyses with different scales from laboratory to in-situ conditions including large deformation phases (e.g. CPT or caisson penetration for validations) have not been reported.

The Combined Lagrangian-SPH method (CLSPH) is adopted hereafter to take into account large deformations. The study focuses on the condition of a regular wave loading with the frequency usually varying from 0.2 to $0.35 \mathrm{~Hz}$. For the case of sand foundation which is highly permeable, it is reasonable to consider a drained condition for the design. The SIMSAND critical state elastoplastic constitutive model is used to describe in a realistic way the sand characteristics, the evolving failure envelope and the influence of different soil parameters (density, friction angle, deformability and grain crushability). The SIMSAND soil parameters are calibrated from triaxial tests on Baskarp sand. The CLSPH-SIMSAND numerical model is then validated using a cone penetration test, model tests and a reduced scale field test. A large number of finite element simulations are then carried out to investigate the behaviour of a caisson foundation in sand subjected to different load combinations. In order to identify the failure envelope in the $H-M-V$ space, radial displacement loadings are applied. Various factors affecting the shape and size of the failure envelope are considered, including soil density, friction strength, soil stiffness, grain breakage, foundation geometry and aspect ratio. The coupling relationships among geometry, aspect ratio and characteristic parameters of the failure envelope are quantified with a general equation. An analytical formula of the 3D failure surface is finally proposed, useful for design purposes and the development of macroelements.

\section{CLSPH - SIMSAND numerical modeling strategy}

\subsection{The Combined Lagrangian - SPH method (CLSPH)}

The Smooth Particle Hydrodynamics (SPH) method was initially developed by Gingold and Monaghan (1977) for numerical analysis in the field of astrophysics. Further developments allowed for applications in solid mechanics. In the SPH method, the computational domain is modelled by a set of discrete particles. The particles have a kernel function to determine their interaction range, which is called the influence domain. Each particle has a volume and a mass and carries several properties such as acceleration, velocity, void ratio etc. (Chen and Qiu, 2012). The interpolation process is based on the following integral representation of a field function $f(x)$ : 

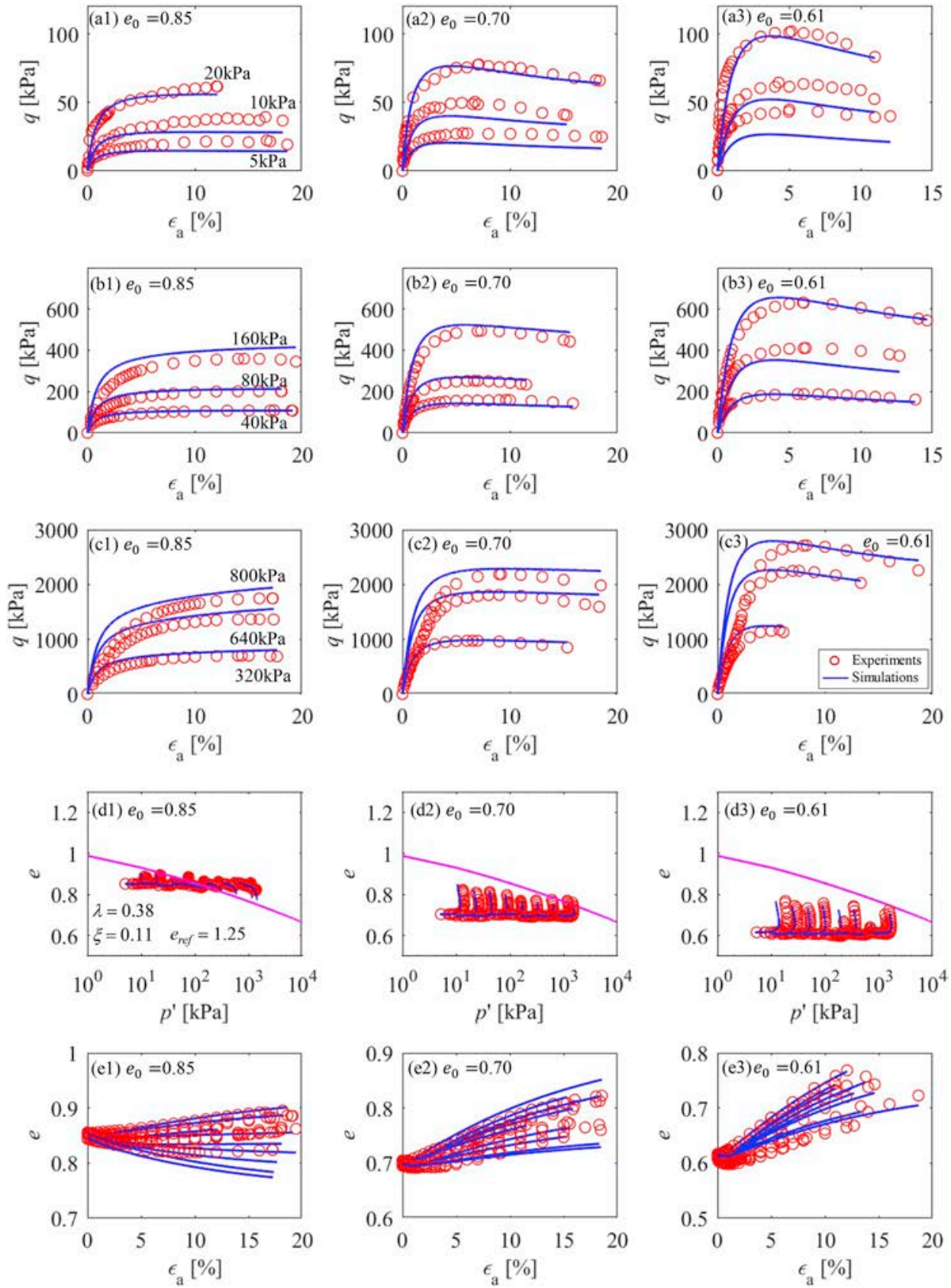

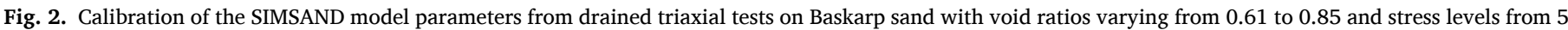

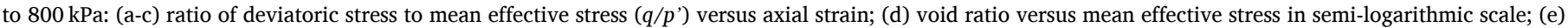
void ratio versus axial strain.

Table 2

Calibrated parameters of the SIMSAND model for the Baskarp sand.

\begin{tabular}{lll}
\hline Parameters & Name & Value \\
\hline$K_{0}$ & Referential bulk modulus (dimensionless) & 344 \\
$v$ & Poisson's ratio & 0.25 \\
$n$ & Elastic constant controlling the nonlinear stiffness & 0.58 \\
$\varphi_{c}$ & Critical state friction angle & 35.1 \\
$e_{\text {ref }}$ & Initial critical state void ratio & 1.25 \\
$\lambda$ & First constant controlling the nonlinearity of CSL & 0.38 \\
$\xi$ & Second constant controlling the nonlinearity of CSL & 0.11 \\
$A_{\mathrm{d}}$ & Constant of magnitude of the stress-dilatancy & 0.45 \\
$k_{\mathrm{p}}$ & Plastic modulus related constant & 0.0034 \\
\hline
\end{tabular}

$$
f x \quad \int_{\Omega} f x^{\prime} W x \quad x^{\prime}, h d x^{\prime}
$$

where $x$ represents the location of the particle; $\Omega$ is the influence domain of the integral; $W$ is the basis function of the approximation, also called the kernel or smoothing function; and $h$ is the smoothing length, which controls the influence domain of $W . f x$ is further approximated by the summation over neighbouring particles as follows:

$f x \quad \sum_{i=1}^{N} f x_{i} W x \quad x_{i}, h V_{i} \quad \sum_{i=1}^{N} f x_{i} W x \quad x_{i}, h \frac{m_{i}}{\rho_{i}}$

where $V_{\mathrm{i}}, \rho_{\mathrm{i}}$ and $m_{\mathrm{i}}$ represent the volume, density and mass of the particle $i$ respectively; $N$ is the number of influencing particles. The spatial derivative of $f x$ is approximated by differential operations on the 


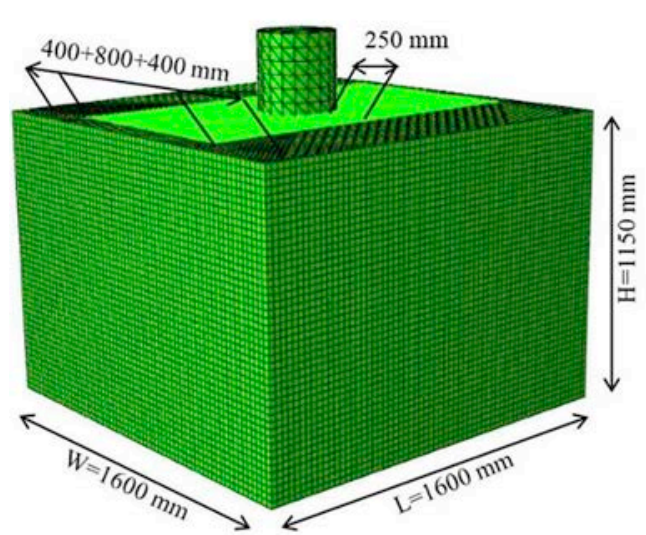

(a)

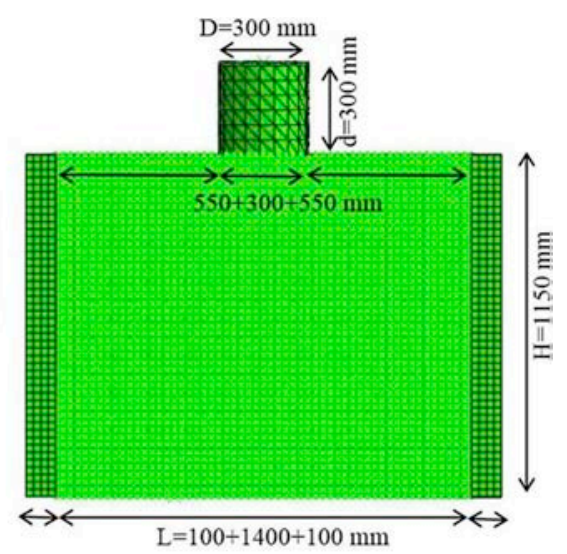

(b)

Fig. 3. Combined Lagrangian-SPH model for the indoor model tests: (a) 3D mesh, and (b) middle cross section.

smoothing function:

$\frac{\partial f x}{\partial x} \quad \sum_{i=1}^{N} \frac{m_{i}}{\rho_{i}} f x_{i} \frac{\partial W x \quad x_{i}, h}{\partial x_{i}}$

The efficiency and accuracy of the SPH method depend on the kernel function. The particles are used as interpolation points to estimate all variables in a continuum. Great distances can separate the SPH particles and the variables between the particles can be approximated by smoothing shape functions. When a particle reaches a certain distance, called smoothing length $h$, from another particle, the two particles start to interact. A smoother or more continuous behaviour can therefore be achieved with a larger smoothing length. On the contrary, a smaller smoothing length results in a more discrete behaviour.

The major advantage of the SPH method is that there is no need for a fixed computational grid when calculating spatial derivatives. An analytical expression based on the derivative of the smoothing function can be used instead (Li and Liu, 2002). Since the particles interact, the $\mathrm{SPH}$ method can deal with very large deformations. The SPH method is complementary approach with respect to the Arbitrary Lagragian Euler (ALE) method. The ALE method relies on physically meshing the environment and tends to be more cumbersome to set up. When the ALE mesh is too distorted to produce good results (for example in the case of CPT or caisson penetration), SPH is a good alternative method of choice. The coupled Eulerian-Lagrangian (CEL) method is also a good choice for considering large deformation on soil-structure interaction. However, the CEL method needs to preset a large Euler domain according to the calculation basis of CEL method. The Euler mesh should be dense enough so as to obtain good precision (Abaqus, 2014). In this study, choosing SPH method costs less computational resources and has higher calculation efficiency while comparing to CEL. Comparing to the classical Lagrangian approach, the main disadvantage of the SPH method is its computational demands (Bojanowski, 2014). It is also less accurate under small deformations.

For all the above reasons, the choice hereafter is discretized only a portion of the computational domain with the SPH method, while classical Lagrangian finite elements are used for the remaining (Combined Lagrangian-SPH approach, CLSPH). The CLSPH method is already implemented into the commercial finite element code ABAQUS. No relative motion is allowed between the SPH and the Lagrangian domains (via the function "Tie Constraint"). This allows to fuse the two domains even if the meshes are different. Detailed information of the CLSPH method can be found in (Abaqus, 2014).

\subsection{The critical state soil model SIMSAND}

The SIMSAND soil model is based on the Mohr-Coulomb model by implementing the critical state concept (Yin et al., 2017a; Jin et al., 2017) with non-linear elasticity, non-linear plastic hardening and a simplified three-dimensional strength criterion. The state-dependent peak strength and stress-dilatancy (contraction or dilation) are well captured by the SIMSAND model (Jin et al., 2017). The basic constitutive equations of the SIMSAND soil model are summarized in Table 1.

The SIMSAND soil model is implemented into ABAQUS/Explicit as a user-defined material model via a user material subroutine VUMAT and can be used with the CLSPH method. Model implementation follows the work of Hibbitt et al. (2001). In ABAQUS/Explicit, the element strain increment $\Delta \varepsilon$ at $\Delta t$ is first given using an explicit time central-differential integration method. Then, the stress increment $\Delta \sigma$ is updated through the material subroutine VUMAT. The cutting plane algorithm proposed by Ortiz and Simo (1986) is adopted for the stress integration. The SIMSAND model can then be adopted in SPH which was validated by modelling the large deformation of granular collapse (Yin et al., 2018).

In the following, the implementation of the CLSPH-SIMSAND approach is first validated using conventional drained triaxial tests, indoor model tests and a field test.

\section{Validation of the CLSPH-SIMSAND approach}

\subsection{Drained triaxial tests}

The calibration of the constitutive model parameters can be carried out using the straightforward method from experimental results (Wu et al., 2017) or using optimisation methods (Jin et al., 2016a,b; Yin et al., 2017b). In this paper, the experimental results of conventional drained triaxial tests on Baskarp sand (named Aalborg University Sand No 0) by Houlsby et al. (2005) are used. For the triaxial experiments, three void ratios $(0.85,0.70,0.61)$ and nine stress levels $(5 \mathrm{kPa}, 10 \mathrm{kPa}$, $20 \mathrm{kPa}, 40 \mathrm{kPa}, 80 \mathrm{kPa}, 160 \mathrm{kPa}, 320 \mathrm{kPa}, 640 \mathrm{kPa}, 800 \mathrm{kPa}$ ), 27 groups in total, were tested.

A typical value of Poison's ratio $v \quad 0.25$ is assumed. The other two elastic parameters $\left(K_{0}, n\right)$ are determined with an isotropic compression test (see Fig. 1). The critical state line related parameters $e_{\text {ref }}, \lambda, \zeta$ are measured from the position of the critical states in the $p^{\prime}-e$ plane (Fig. 2 (d)). Other parameters are calibrated manually from tests on sand with a void ratio $e_{0} \quad 0.85$ (Wu et al., 2017). All the calibrated parameters are summarized in Table 2 . Using these values, additional tests $\left(e_{0} \quad 0.7\right.$, 0.61 ) are simulated demonstrating the good performance of the model (see Fig. 2).

Since the experimental validation of the model covers a wide range from very low level of confining stress (e.g. $5 \mathrm{kPa}$ ), the model with identified parameters is applicable for simulating both small scale model 


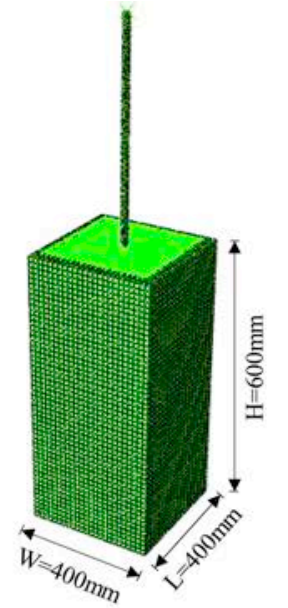

(a) combined Lagrangian-SPH model

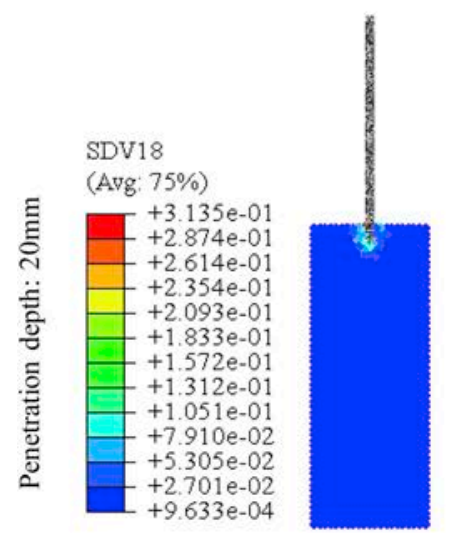

(c) Plastic deviatoric strain

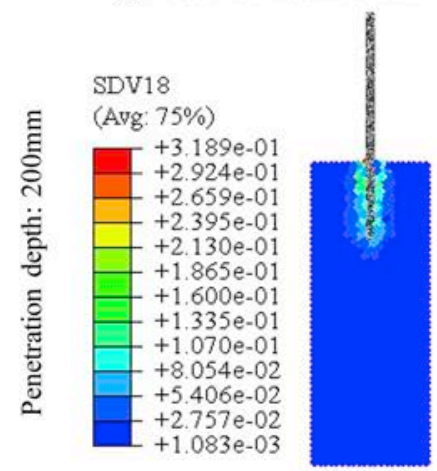

(f) Plastic deviatoric strain

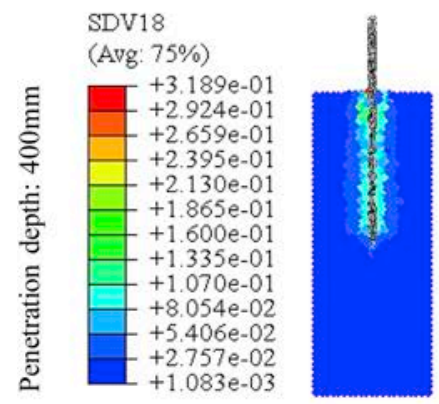

(i) Plastic deviatoric strain

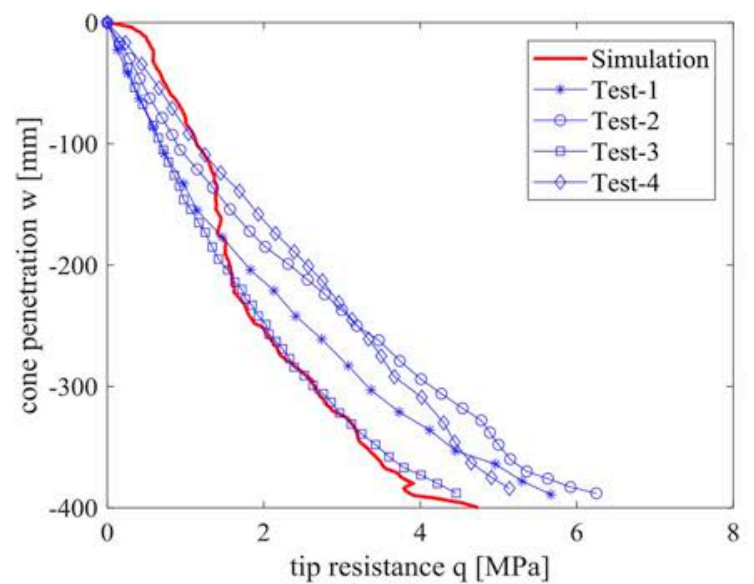

(b) comparison of $\mathrm{q}-\mathrm{w}$ curves between experiments and simulation

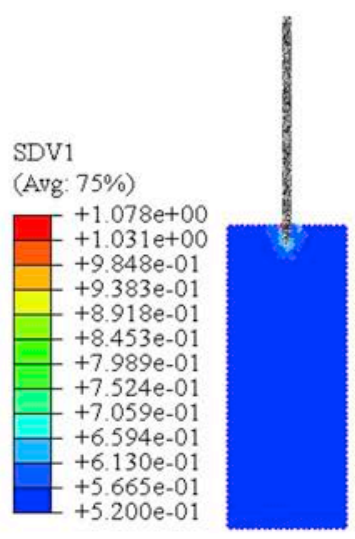

(d) Void ratio

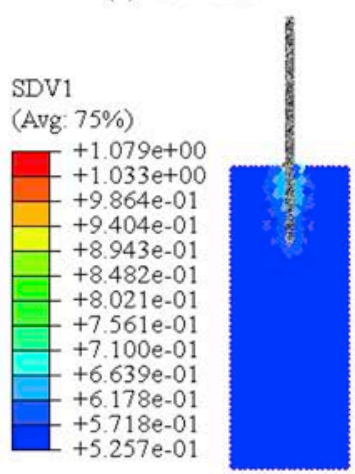

(g) Void ratio

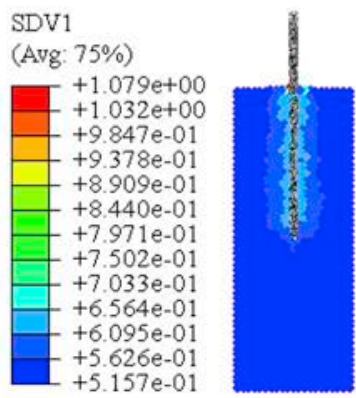

(j) Void ratio

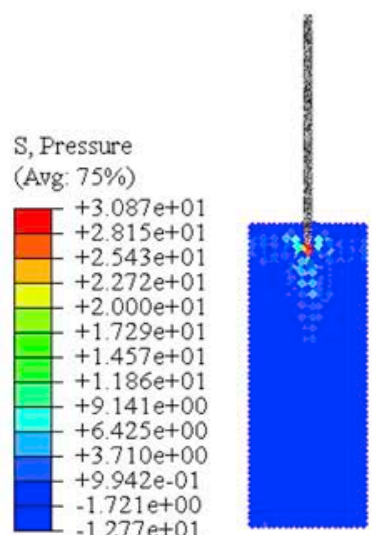

(e) Mean effective stress

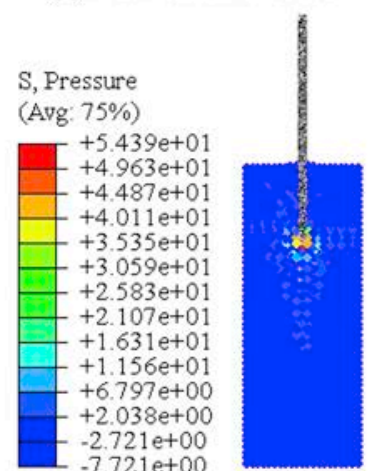

(h) Mean effective stress

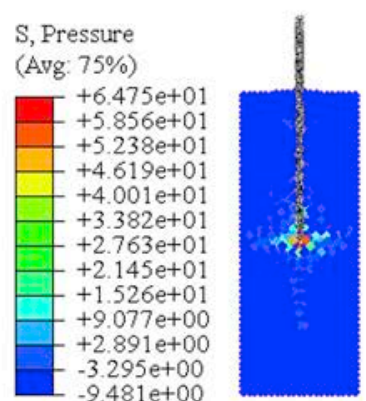

(k) Mean effective stress

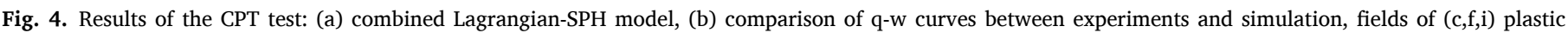
deviatoric strain, $(\mathrm{d}, \mathrm{g}, \mathrm{j})$ void ratio, $(\mathrm{e}, \mathrm{h}, \mathrm{k})$ mean effective stress during peneration 


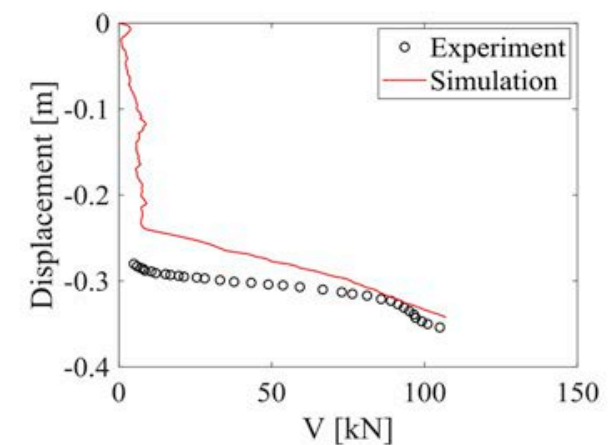

(a)

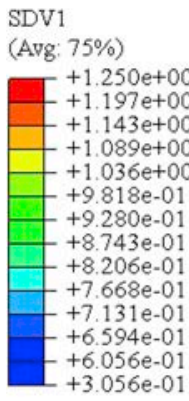

SDV18

(Avg: 75\%)

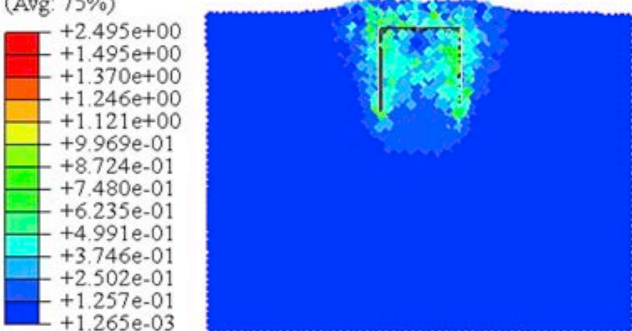

(b)

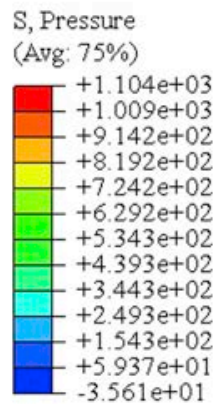

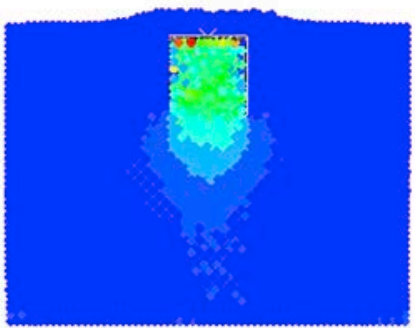

(d)

(c)

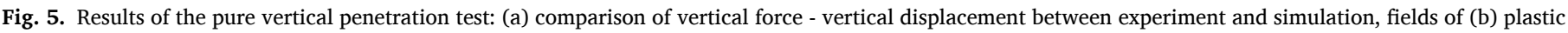
deviatoric strain, (c) void ratio and (d) mean effective stress at the end of the vertical penetration test.

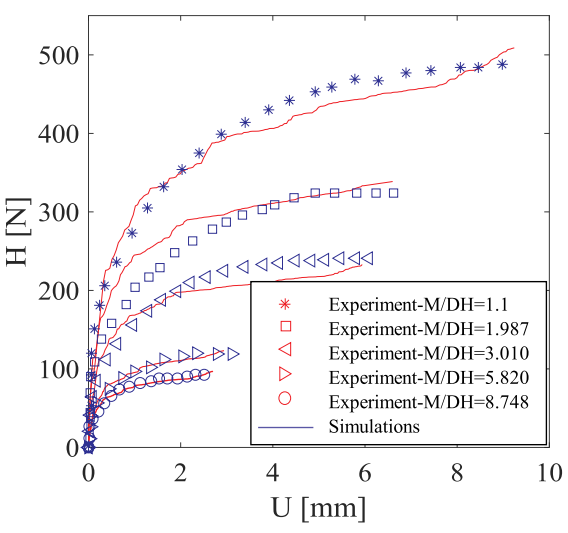

(a)

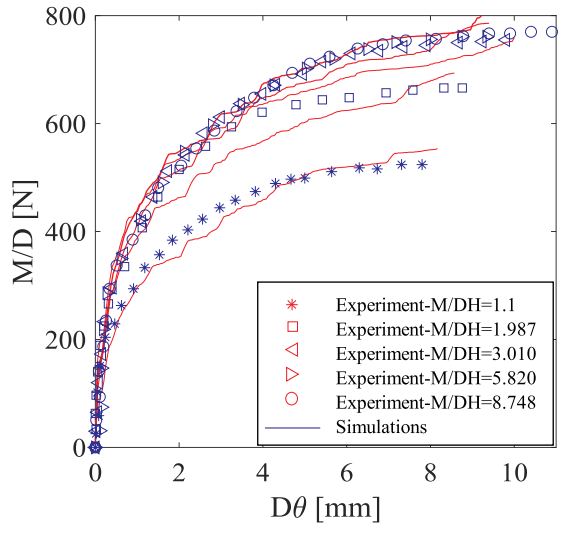

(b)

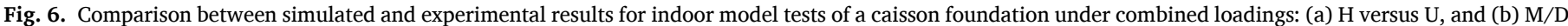
versus $\mathrm{D} \theta$.

tests and real size field tests in Baskarp sand.

\subsection{Indoor model tests}

\subsubsection{Experimental setup}

A well-documented series of laboratory tests of a caisson foundation in sand including the installation phase and the application of monotonic loadings Foglia et al. (2015) is simulated hereafter. The experimental set-up consists of a sand box (1600 mm $1600 \mathrm{~mm} 1150 \mathrm{~mm})$, a loading frame and a hinged beam. A system of steel cables and pulleys induces loadings to the foundation through an electric motor drive placed on the hinged beam. The load, set by means of three weight hangers, is transferred to the foundation through a vertical beam bolted on the caisson lid. The foundation is instrumented with three Linear
Variable Differential Transformers (LVDTs) and two load cells. The caisson foundation is made of steel, with an outer diameter of $300 \mathrm{~mm}$, a lid thickness of $11.5 \mathrm{~mm}$, a skirt length of $300 \mathrm{~mm}$ and a skirt thickness of $1.5 \mathrm{~mm}$.

A Cone Penetration Test (CPT) is first carried out to estimate the soil parameters. Six tests are then performed under different monotonic loading combinations (one pure vertical load up to failure and various dimensionally homogeneous moment to horizontal load ratios ( $M$ / DH $1.1,1.987,3.01,5.82,8.748)$ at constant vertical load).

\subsubsection{Numerical model}

The numerical model has the same dimensions as the experimental sand box, see Fig. 3. The horizontal displacements of the lateral sides and the translational degrees of freedom on the bottom are constrained. 


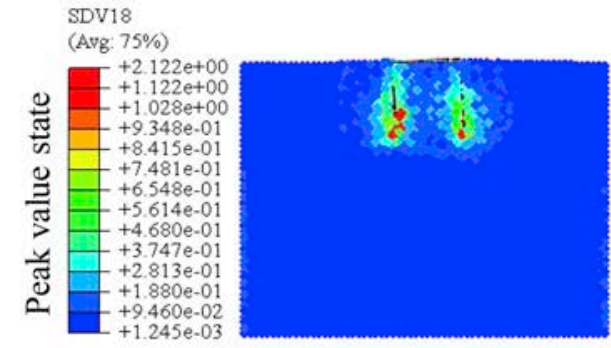

(a) Plastic deviatoric strain

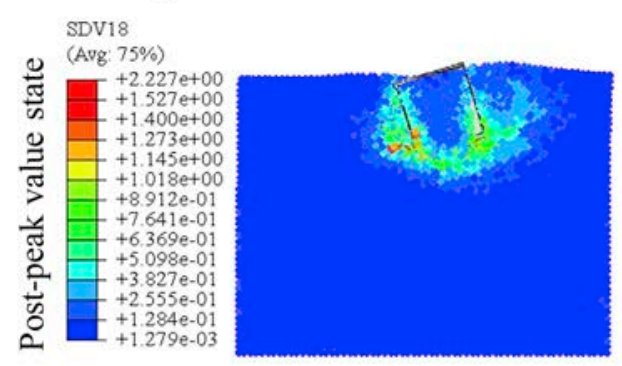

(d) Plastic deviatoric strain

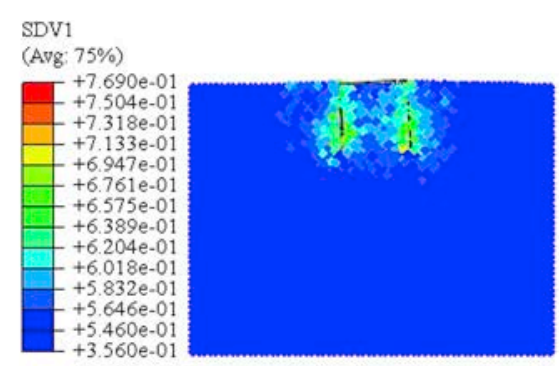

(b) Void ratio

SDV1

(Avg: 75\%)

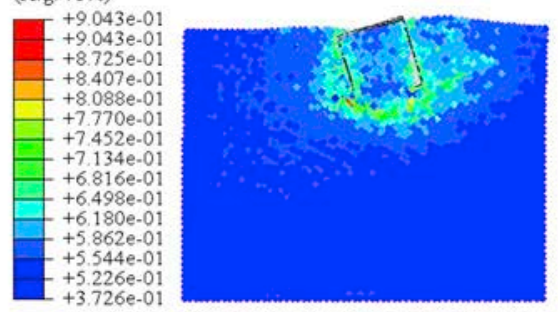

(e) Void ratio

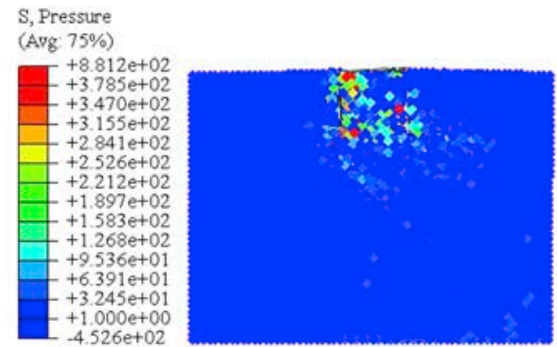

(c) Mean effective stress S, Pressure (Avg: 75\%)

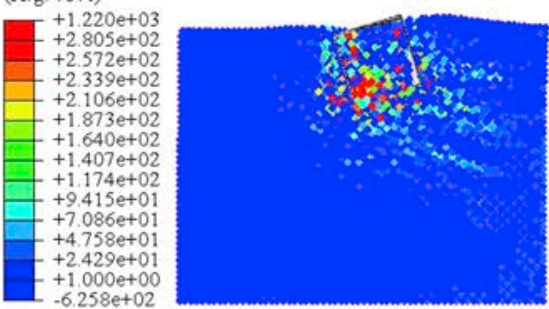

(f) Mean effective stress

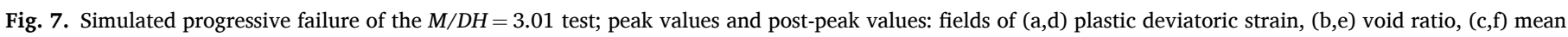
effective stress.

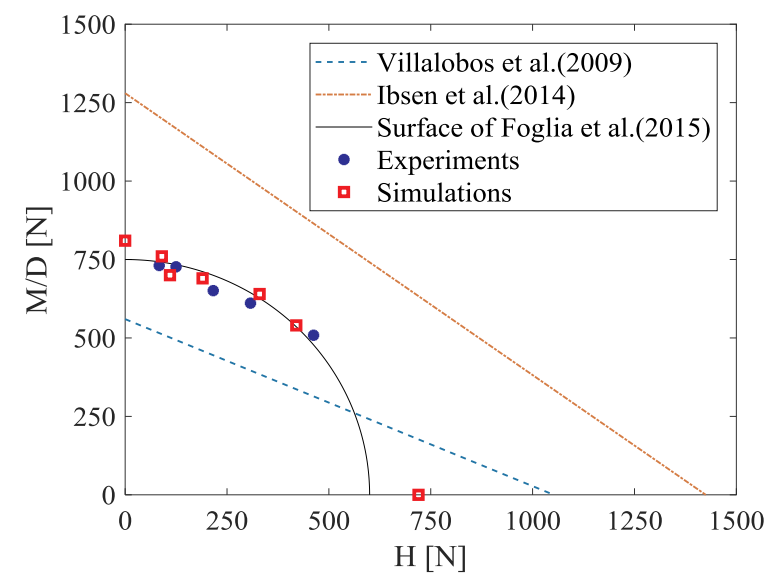

Fig. 8. Comparison between simulated and experimental results; failure envelopes on the $H: M / D$ loading plane.
The main parameters of the finite element model are summarized in Table 2 .

In the Combined Lagrangian - SPH model, the part of the soil that experiences large deformations is modelled with SPH particles (see Fig. 3). The SPH domain has a length of $1400 \mathrm{~mm}$ at the side where the horizontal or moment loading is applied, a width of $800 \mathrm{~mm}$, a height of $1150 \mathrm{~mm}$ and a total number of 88407 particles. The outer Lagrangian domain is modelled with 105984 hexahedral elements. The size of SPH domain in the whole model was examined big enough without boundary effect for all simulations. The SPH domain is densely covered with SPH particles with an initial particle distance in each direction that remains approximately constant to obtain a homogenous configuration. The SPH domain interact with the Lagrangian domain through contact interaction relations defined between a node-based surface (associated with the particles) and an element-based or analytical surface (Abaqus, 2014).

The caisson has the same size as in the experiment and is modelled with 927 rigid tetrahedron elements. The density of the steel made

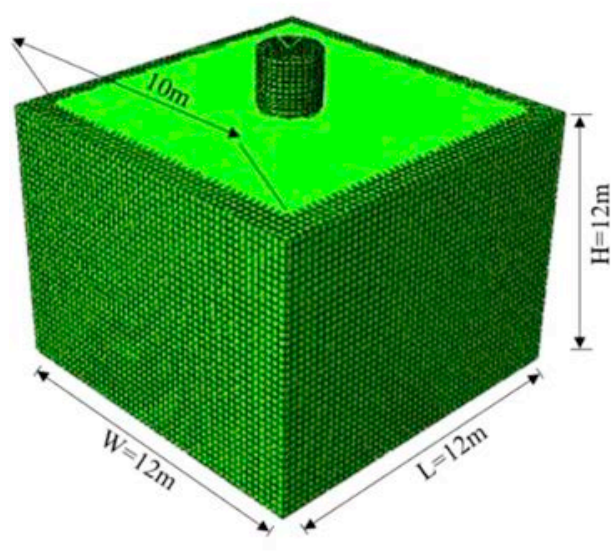

(a)

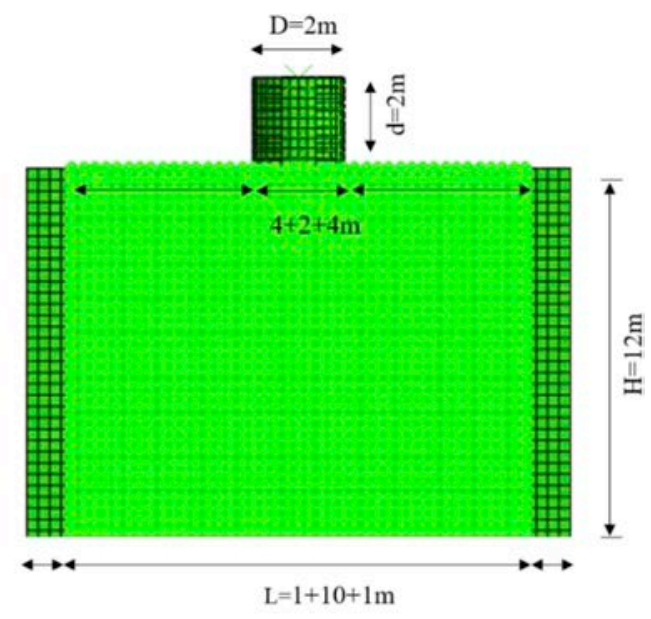

(b)

Fig. 9. Combined Lagrangian-SPH model for the field test: (a) 3D mesh, and (b) middle cross section. 


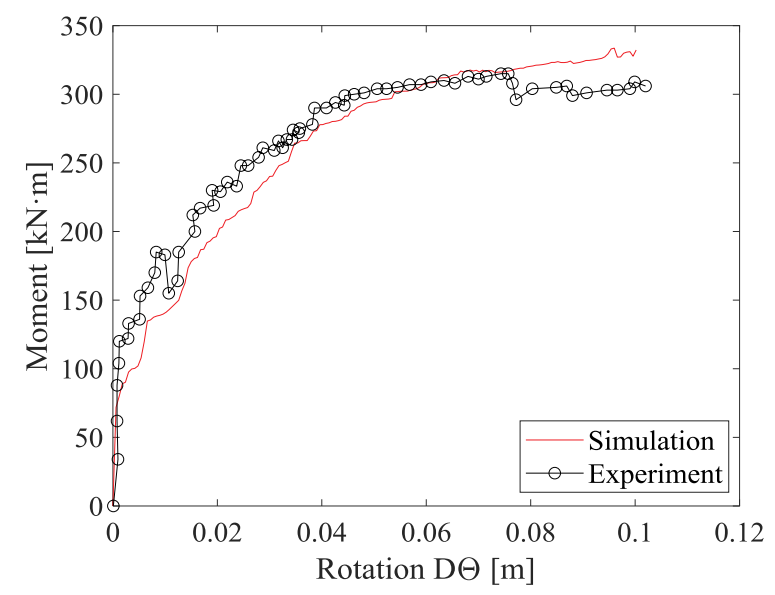

Fig. 10. Comparison between simulated results and field measurements: moment $M$ and rotation $D \theta$ curve.

caisson is $7800 \mathrm{~kg} / \mathrm{m}^{3}$, the Young modulus $200 \mathrm{GPa}$ and the Poisson ratio 0.3 , see Foglia et al. (2015). The caisson is initially located on the soil surface at the centre of the box. For the CPT simulation, the caisson is replaced by a cylinder bar (modelled with 807 rigid tetrahedron elements) with a diameter of $20 \mathrm{~mm}$ and a 60 cone at the bottom, see Foglia et al. (2015).

\subsubsection{CPT simulation results}

In order to validate the CLSPH-SIMSAND numerical model, the CPT test is simulated hereafter. Following Houlsby et al. (2006), the cone penetration applied velocity is taken equal to $5 \mathrm{~mm} / \mathrm{s}$. Assuming a typical soil-structure interface friction coefficient, a rigid Mohr-Coulomb type interface model is adopted and the interface model is applied on the entire (tip and shaft) surface of the cone, see Fig. 4(a).

Fig. 4(b) presents the simulation results and the comparison with four groups of CPT data, Foglia et al. (2015). Note that an unideal agreement is observed between the simulated CPT penetration and the test for the top $200 \mathrm{~mm}$. One possible reason might be the dynamic fluctuation while adopting explicit algorithm. Besides, at the beginning of penetration, due to the tiny size of the pile head, there might be disturbance on the interface between the cone and the soil. As the penetration continues, the trend turned to be similar with the test data. In general, the simulation result indicates that the CLSPH-SIMSAND model with calibrated material parameters performs in an acceptable manner. The plastic deviatoric strain (SDV18), the void ratio (SDV1) and the mean effective stress (S Pressure, $\mathrm{kPa}$ ) fields corresponding to a penetration of $20 \mathrm{~mm}, 200 \mathrm{~mm}$ and $400 \mathrm{~mm}$ are plotted in Fig. 4(c)-(k). The fields of mean effective stress demonstrate clearly the phenomena of cavity expansion with the increase of mean effective stress around the tip of CPT. All results show reasonable distributions with an influence distance much smaller than the SPH domain.

\subsubsection{Caisson foundation simulation results}

The combined Lagrangian - SPH model in Fig. 3 is hereafter used to simulate a vertical penetration test with a vertical displacement control at a rate of $5 \mathrm{~mm} / \mathrm{s}$, and five tests at various dimensionally homogeneous moment to horizontal load ratios $(M / D H \quad 1.1,1.987,3.01,5.82,8.748)$ at a constant vertical load of $241 \mathrm{~N}$. The horizontal displacements and the rotations are applied at the middle point of the caisson. A relatively slow displacement rate of $10 \mathrm{~mm} / \mathrm{s}$ and a rotation rate of $0.5 / \mathrm{s}$ are chosen to eliminate the dynamic effects. All monotonic loading paths are followed until the vertical bearing capacity $(V M)$ or the horizontal capacity and moment capacity $(M R)$ are reached.

The applied vertical force versus the vertical displacement for the penetration test is plotted in Fig. 5. The results of five typical $M / D H$ values $(1.100,1.987,3.010,5.820$ and 8.748) are shown in Fig. 6. For all five cases the horizontal load $(H)$ versus the horizontal displacement $(U)$ and the dimensionally homogeneous moment $(M / D)$ versus the rotations $(D \theta)$ are plotted. A good agreement is obtained for all tests between experiments and simulations, showing the good performance of the CLSPH-SIMSAND approach.

An extreme case is selected hereafter to check the behaviour of the model under large deformations: the moment horizontal loading test $M$ / DH 3.010. The plastic deviatoric strain (SDV18), the void ratio (SDV1) and the mean effective stress (S Pressure, $\mathrm{kPa}$ ) fields at the end of loading are plotted in Fig. 7(a)-(c). To further examine the progressive failure, a larger displacement and rotation are applied till the appearance of sliding at the bottom. The corresponding fields of plastic deviatoric strain, void ratio and mean effective stress at large deformation are plotted in Fig. 7(d)-(f). All results show reasonable field distributions with an influence distance, in the vertical and horizontal directions, much smaller than the SPH particles domain.

The failure envelopes on the $H: M / D$ loading plane of Villalobos et al. (2010), Ibsen et al.(2014) and Foglia et al.(2015) are plotted in Fig. 8 and compared with the numerical simulations for the same vertical loading. A good agreement is again observed.

\subsection{Field test}

\subsubsection{Experimental setup}

In order to further validate the numerical model, a reduced scale field test conducted by Houlsby et al. (2005) is simulated hereafter. A steel caisson with an outer diameter of $2 \mathrm{~m}$ and a skirt length of $2 \mathrm{~m}$ was tested. The skirt was made of steel plate $12 \mathrm{~mm}$ thick and the caisson was installed in a shallow pond near the sea to model a bucket foundation. The load eccentricity $h$ and vertical load $V$ were $17.4 \mathrm{~m}$ and $37.3 \mathrm{kN}$, respectively. The caisson was installed in dense Baskarp sand area with unit weight $19.5 \mathrm{kN} / \mathrm{m}^{3}$ and specific gravity $26.5 \mathrm{kN} / \mathrm{m}^{3}\left(e_{0} \quad 0.549\right)$ as indicated by (Ibsen et al., 2005). The test contained three phases: installation, loading and dismantling. For the loading phase, an old tower from a wind turbine was mounted on top of the caisson. The caisson was loaded by pulling the tower horizontally with a wire. The combined loading $(H, M)$ was controlled by changing the tower height.

\subsubsection{Numerical model}

The caisson is modelled using rigid hexahedron elements with the same dimensions and thickness as in the experiment (see Fig. 9), while the behaviour of the sand is reproduced with the SIMSAND model, see Table 2. The interface behaviour between the caisson and the soil is modelled with a classical Coulomb model, where the tangential frictional stress is assumed proportional to the normal stress. Large deformations and geometric non-linearities are considered. The modelling strategy is similar to that of the indoor model tests (combined Lagrangian - SPH model).

The calculation domain is composed of two parts: the inner SPH domain and the outer Lagrangian domain. The SPH domain has a length of $10 \mathrm{~m}$ (horizontal direction), a height of $12 \mathrm{~m}$ and a total number of 106840 particles. The Lagrangian part is discretized with 32670 hexahedral elements. The SPH domain interacts with the Lagrangian finite element domain via contact interfaces that can open and close (Abaqus, 2014). More specifically and due to the lack of experimental data for the limit stress in the tangential direction, no threshold $\left(\tau_{\max }\right)$ on the tangential frictional stress is adopted. The contact behaviour between the caisson and the soil is modelled by a rigid friction model with a friction coefficient $\mu \quad \tan \left(\varphi_{\mathrm{c}} / 2\right) \quad 0.32$, where the soil critical friction angle is $\varphi_{\mathrm{c}} 35.1$. A penalty algorithm is adopted for the contact behaviour (Hibbitt et al., 2001). Theoretically, the separation between soil and caisson is allowed. In our cases, the caisson and the soil have not separated during the penetration because of the existence of confining stress and the small thickness of the caisson. The horizontal displacements of the lateral sides are constrained as well as the translational degrees of freedom at the bottom. The different parameters used for the 


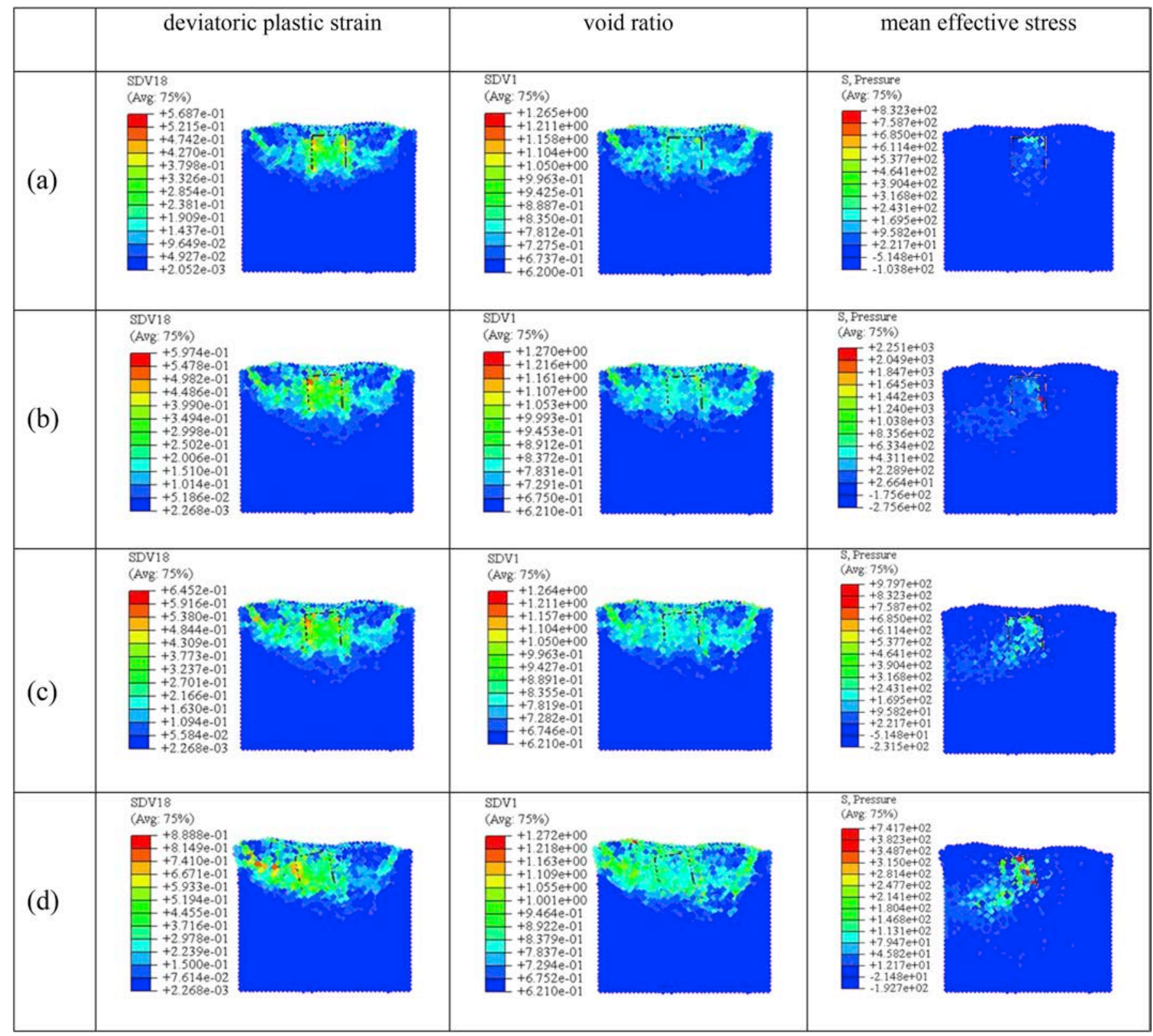

Fig. 11. Simulated results of the field test at different phases: (a) end of penetration, (b) $1 / 2$ of the peak values of the forces, (c) peak values of the forces, and (d) postfailure stage.

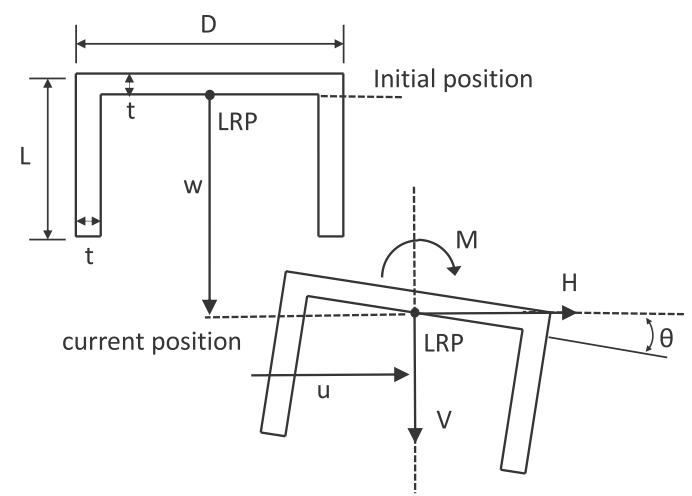

Fig. 12. Loading and displacement conventions for a caisson foundation.

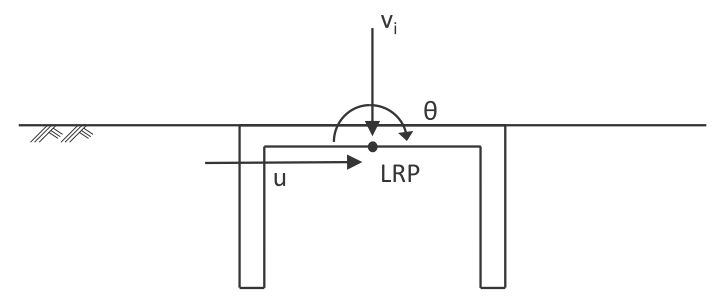

Fig. 13. Schematic plot of radial displacement control.

simulation are summarized in Table 2.

\subsubsection{Caisson foundation simulation results}

A moment-rotation test on the $2 \quad 2 \mathrm{~m}$ caisson is first considered to further prove the robustness of the CLSPH-SIMSAND approach (see Houlsby et al. (2005)). A relatively slow displacement rate of $10 \mathrm{~mm} / \mathrm{s}$ 


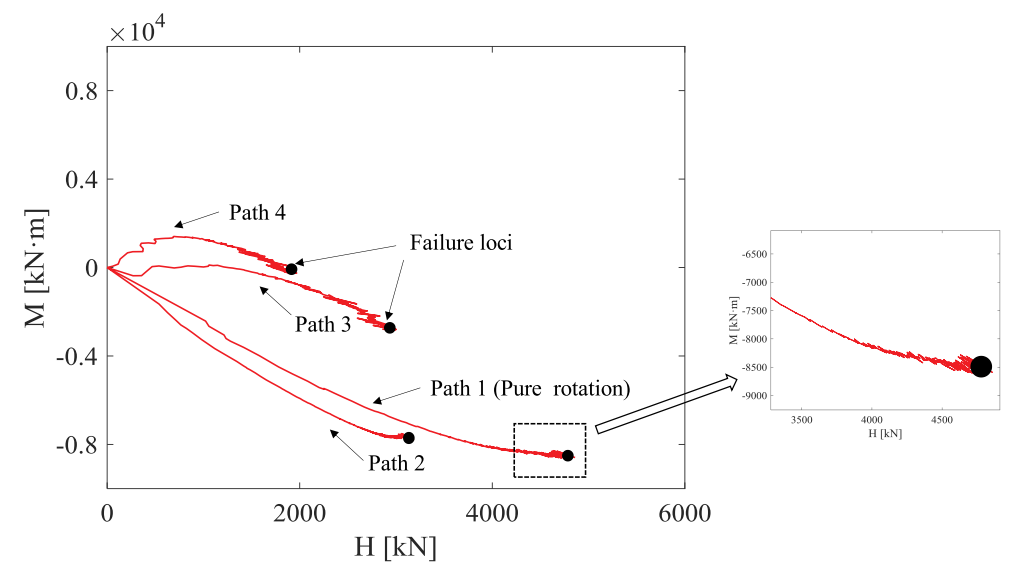

(a)

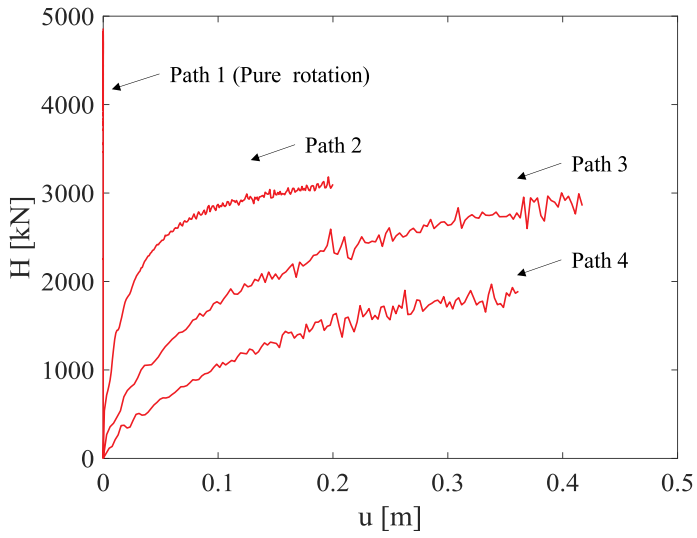

(b)

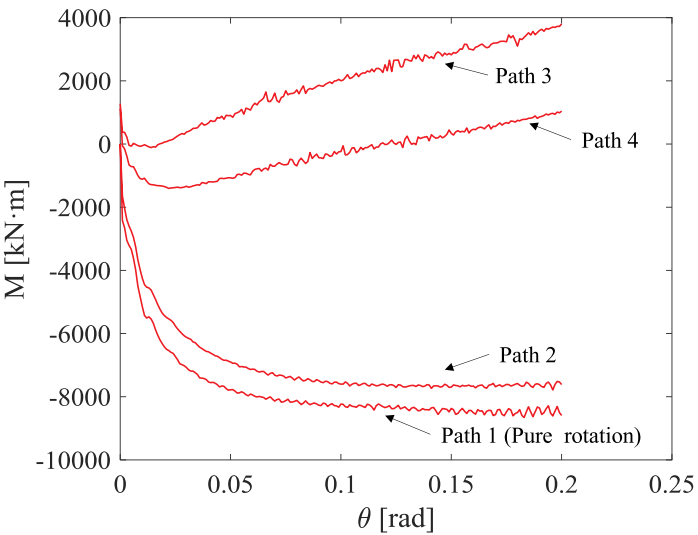

(c)

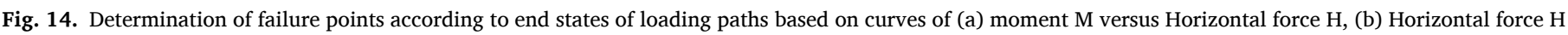
versus displacement $\mathrm{u}$, and (c) moment $\mathrm{M}$ versus rotation $\theta$
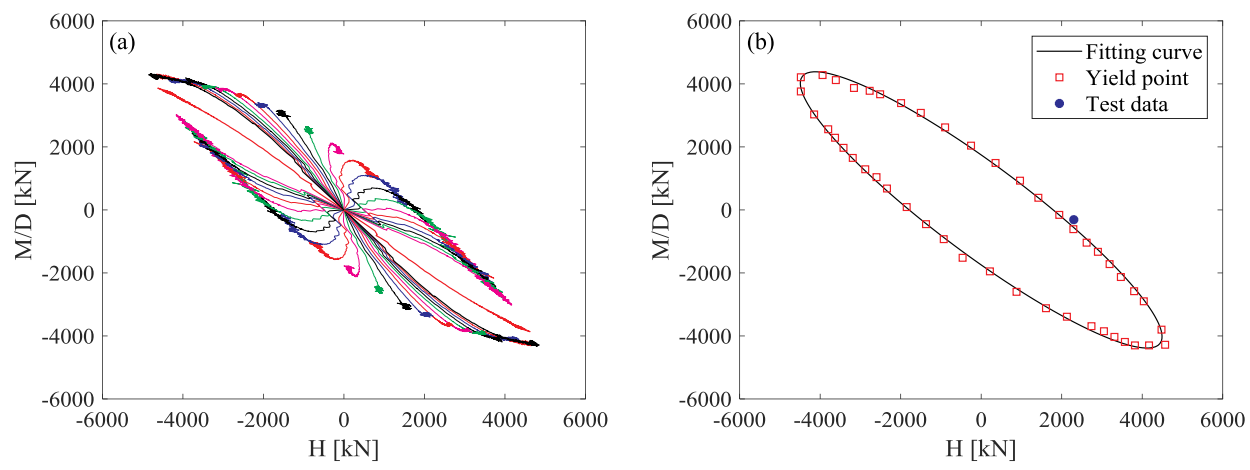

Fig. 15. Numerical results of radial displacement control tests in the $H$ - $M$ plane: (a) load paths, and (b) failure surface.

and a rotation rate of $0.5 / \mathrm{s}$ are applied to eliminate dynamic effects. Numerical results are compared with the experimental results in Fig. 10. The performance of the model is again satisfactory. The numerical model reproduces correctly not only the moment evolution but also the bearing capacity of the caisson.

An extreme case is shown hereafter to analyse the progressive failure of the field test. The simulation is composed of two steps: the caisson foundation is first installed to the specified depth; then, a displacement rate of $10 \mathrm{~mm} / \mathrm{s}$ and rotation rate of $0.5 / \mathrm{s}$ are applied up to the ultimate strength. The plastic deviatoric strain (SDV18), the void ratio (SDV1) and the mean effective stress (S Pressure, $\mathrm{kPa}$ ) fields are shown in Fig. 11 for the different phases. It is obvious that the area of these three variables increases with increasing applied displacement. The peak value also increases with time. The CLSPH-SIMSAND approach again successfully reproduces the progressive failure of the caisson foundation.

In the following and based on the previous satisfactory validation results, the CLSPH-SIMSAND approach is adopted to numerically reproduce the $H-M-V$ failure envelope of a caisson foundation for different soil properties and foundation geometries.

\section{Numerical study of the failure envelope in $H-M$ plane}

\subsection{Loading procedure}

In order to identify the failure envelope of a foundation, Gottardi et al. (1999) proposed to follow two loading control paths: (1) Swipe tests 


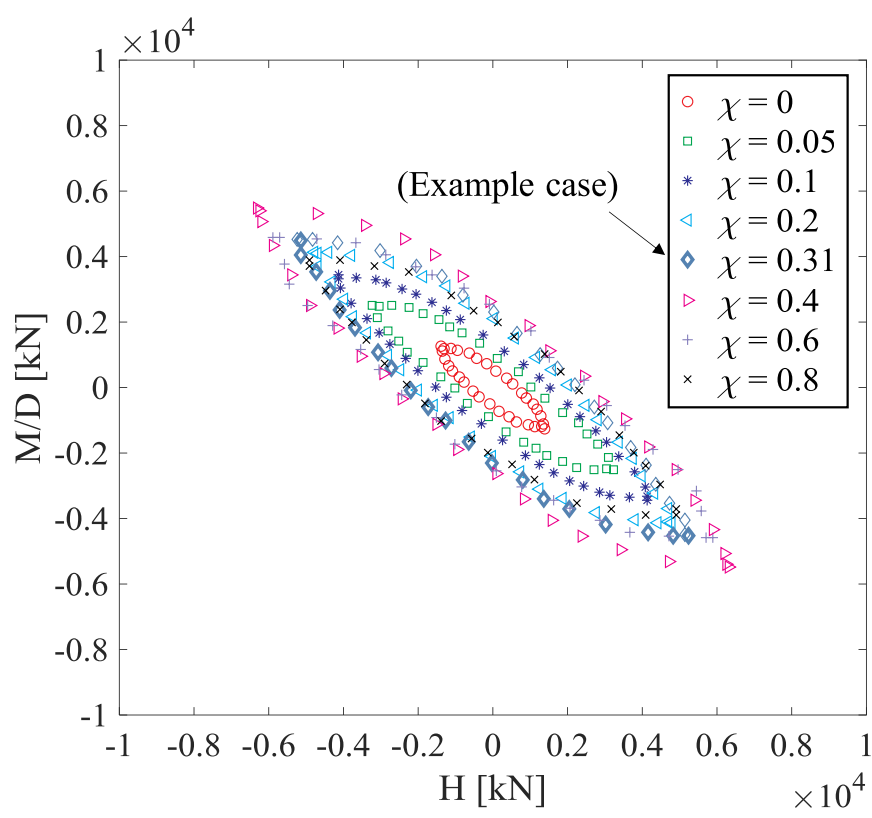

Fig. 16. Failure envelopes at different vertical load levels in the $H-M$ plane.

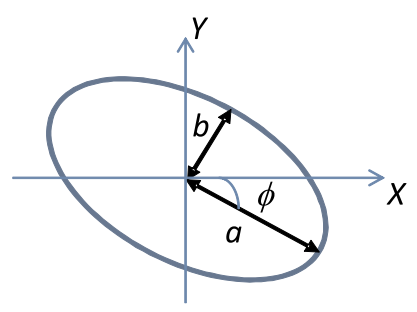

Fig. 17. Schematic plot of the failure envelope and definitions of the characteristic measures $a, b$ and $\varnothing$

in which a vertical displacement is first applied to the foundation up to a certain level of vertical force, and then an increasing horizontal displacement under a constant vertical displacement; (2) Radial displacement tests in which the ratio between the applied displacements or the combined rotation-displacement increments is kept constant.

In this following, numerical radial displacement tests are adopted as the main loading control. The sign conventions for the loads (horizontal force, vertical force and bending moment) applied on the Loading Reference Point (LRP) of the caisson foundation are presented in Fig. 12. The foundation model has an outer diameter $(D)$ of $2 \mathrm{~m}$, a skirt length $(L)$ of $2 \mathrm{~m}$, and a lid and skirt thickness $(t)$ of $12 \mathrm{~mm}$. The main goal of this study being the evaluation of the bearing capacity of the caisson foundation, the wind turbine and the superstructure are not discretized.

OWT caisson foundations are relatively light, with a typical mass of $600 t$ (vertical deadload 6 MN) (Houlsby et al., 2005). The horizontal and overturning moment bearing capacities are therefore important for the design. To investigate the form of the failure surface in the $H-M$ plane, different loading paths are applied hereafter on the LRP of the caisson. As shown in Fig. 13, a constant vertical load is imposed up to a specified value $\chi \quad V_{i} / V_{0}\left(V_{0}\right.$ being the maximum load). Then, radial displacement loadings are applied considering a constant ratio between the combined rotation-displacement increments. The value of the displacement is large enough to ensure that the maximum strength is reached. In the following $\chi \quad 0$ refers to an actual load factor of $\chi \quad 0.01$ (only the caisson self-weight is considered).

Fig. 14 illustrates the way chosen to determine the bearing capacity; the ultimate bearing capacity is defined by the ends of loading paths. Examples of load paths in the $H-M$ plane from the numerical radial displacement tests are shown in Fig. 15. The ratio between the increments of the rotation $\theta$ and the horizontal displacement $u$ is constant $(\delta \theta / \delta u$ constant), which implies a straight loading path (Fig. 15(a)). By connecting the values at the end of the different load paths, the complete failure envelope is obtained, as shown in Fig. 15(b).

Note that, to ensure the radial loading paths approaching close enough to the ultimate capacity diagram, the value of the displacement should be large enough to ensure that the maximum strength is reached. As shown in Fig. 15, the ultimate bearing capacity can be reached for most of the loading paths, and obvious inflection points can be observed for these loading cases. However, for a few loading paths, the ultimate bearing capacity is hard to reach even a large displacement has been occurred. In order to unify the basis of determination, the ultimate bearing capacity is defined by the ends of loading paths, based on which the final failure envelope can then be determined.

Some general results are summarized below: (1) the failure envelopes of caisson foundations in sand are of inclined elliptical shape; and (2) the presence of bending moment has a significant influence on the horizontal bearing capacity depending on the loading direction.

\subsection{Influence of the soil properties}

The influence of various initial state variables and soil parameters soil density, friction strength, soil stiffness and grain breakage - on the failure envelope of a caisson foundation in sand is studied hereafter.

Four initial void ratios $\left(e_{0} \quad \mathbf{0 . 6 2}, 0.67,0.73\right.$ and 0.80 , corresponding to a relative density $D_{r} \quad 80 \%, 60 \%, 40 \%$ and $20 \%$ ), four critical state friction angles $\left(\varphi_{c} 25,30,35.1,40\right)$, four soil stiffness constants $\left(k_{p} \quad 0.01, \mathbf{0 . 0 0 3 4}, 0.001,0.0005\right.$; the bigger value represents the smaller stiffness) and four grain breakage constants $\left(C_{a} \& C_{b} \quad \mathbf{0} \& \mathbf{0}\right.$, $2500 \& 4,7000 \& 7,12000 \& 10)$ are adopted for the simulations. Note that the set $e_{0} \quad 0.62, \varphi_{c} \quad 35.1, k_{p} \quad 0.0034, C_{a} \quad 0$ and $C_{b} \quad 0$ corresponds to the Aalborg University Sand No 0 mentioned above. The grain breakage related constants " $C_{a} \& C_{b} \quad 2500 \& 4,7000$ \& 7, 12000 \& 10", corresponds to different crushabilities of a hypothetical sand (Jin et al., 2018a). Bold letters are used to represent the original parameter group values corresponding to the field test presented in section 3.3 and Table 2. In order to identify the influence of each property, only one of the related input parameters (including the initial state variable $e_{0}$ ) is changed for each numerical simulation while keeping others constant. Three characteristic measures are used to describe the shape and size of the envelope in $H-M$ space. The length of the long axis $a$, the short axis $b$ and the rotation angle $\varnothing$, see Fig. 17.

Fig. 18 presents the original form and the fitting curve of failure envelopes for varying soil densities in the $H-M$ plane. It is worth noting that the obtained failure envelope excluded the field case simulated with the original parameter group (marked in bold). For increasing soil density, the size of the failure envelope expands. In other words, the horizontal and bending moment capacities improve with increasing soil density. A linear relationship can be observed in logarithmic scale between the parameter $a$ and the soil relative density $D_{r}$, Fig. 18(d).

A similar conclusion is obtained regarding the soil friction strength and the stiffness parameters, Figs. 19 and 20. With increasing the critical friction angle the mobilized peak strength during shearing is directly increasing, and thus the size of the failure envelope increases. The plastic modulus related constant $k_{\mathrm{p}}$ is defined as the initial slope of $\mathrm{q} / \mathrm{p}$ ' versus plastic deviatoric strain. Thus, for a given initial mean effective stress, $k_{\mathrm{p}}$ controls the initial shear stiffness. In critical-state-based sand models like SIMSAND model adopted in this study, a smaller value of $k_{p}$ gives a higher shear modulus resulting in a higher mobilized friction angle or peak strength, as indicated by Yin et al. (2013) and Jin et al. (2016a) that this parameter does not affect the critical strength but influences significantly the peak strength. As a result, in finite element simulations of caisson foundation a smaller value of $k_{\mathrm{p}}$ representing a higher peak strength of soils gives a bigger size of failure envelope. Or simply speaking, a higher peak strength of foundation soil mobilizes a 

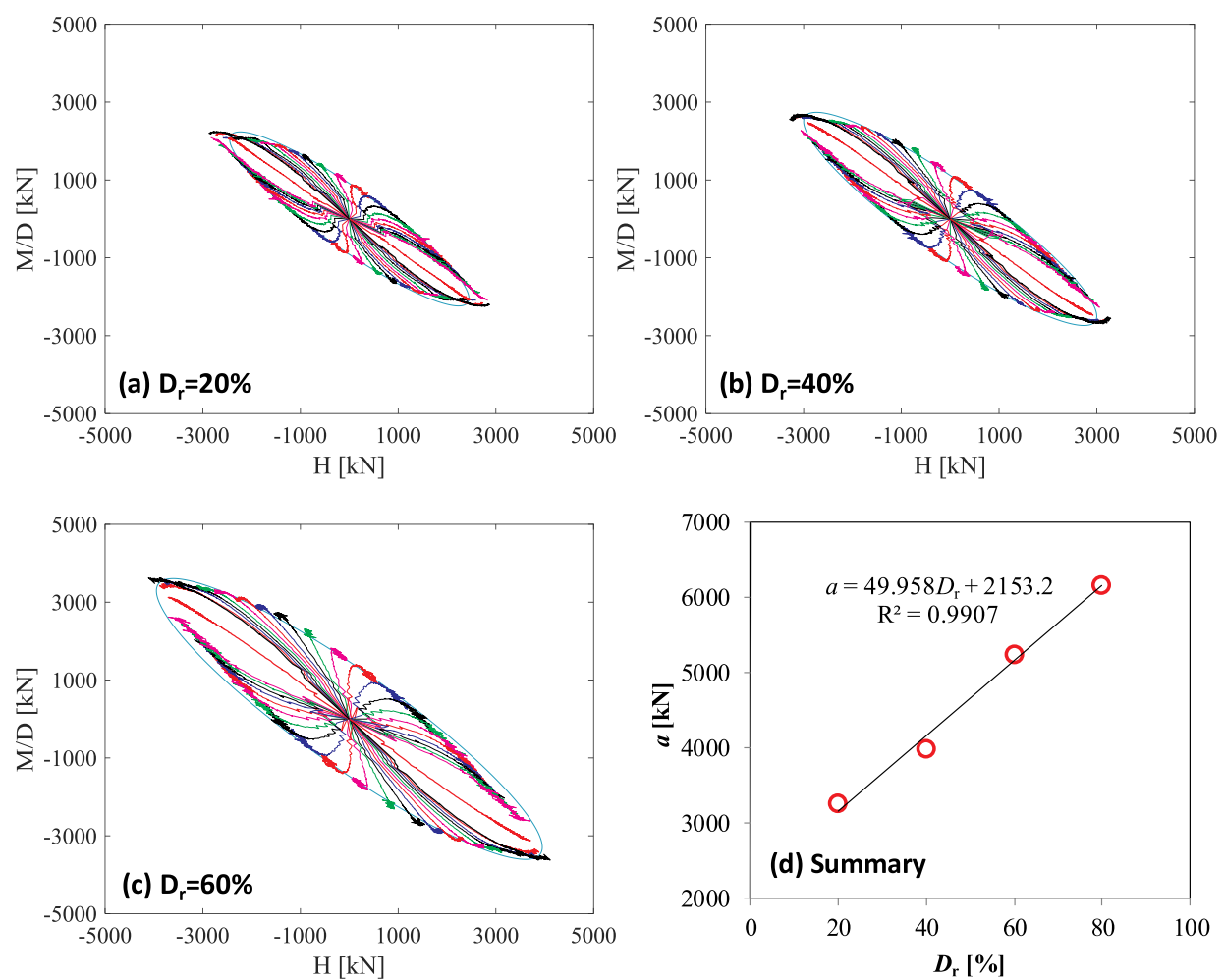

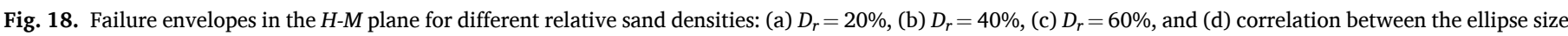
$a$ and $D_{r}$.
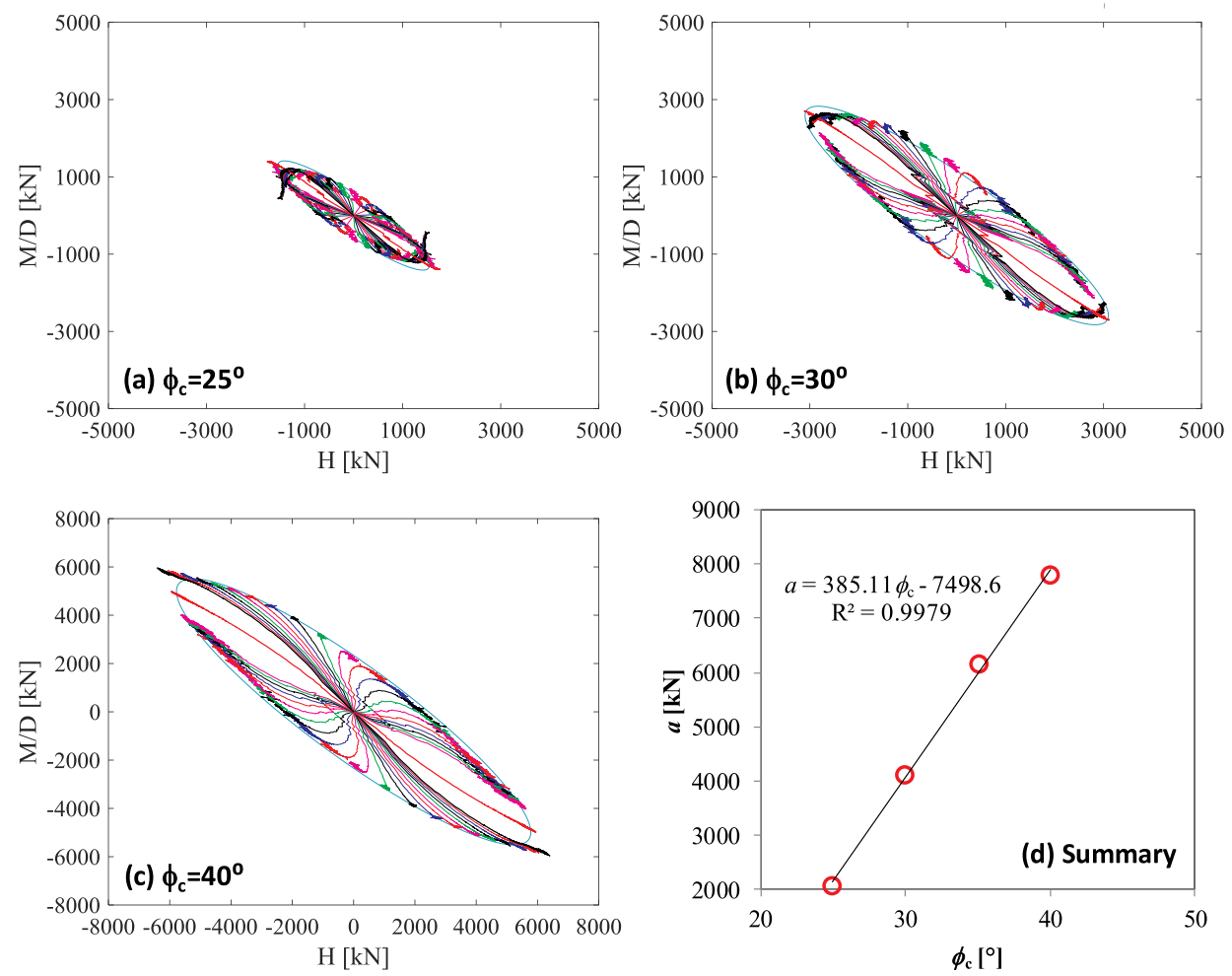

Fig. 19. Failure envelopes in the $H-M$ plane for different sand critical friction angles: (a) $\varphi_{c} \quad 25$, (b) $\varphi_{c} \quad 30$, (c) $\varphi_{c} \quad 40$, and (d) correlation between the ellipse size $a$ and $\varphi_{c}$. 

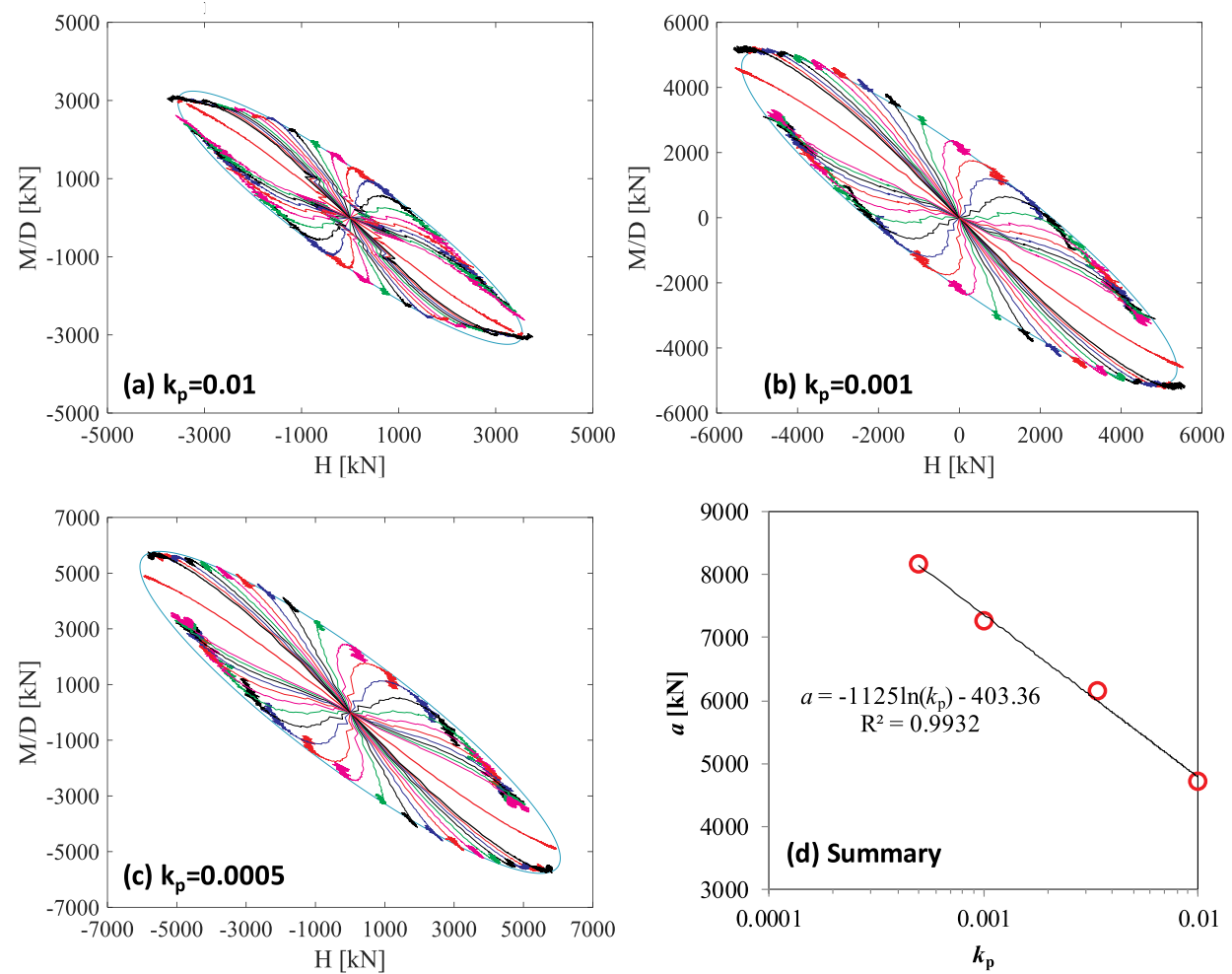

Fig. 20. Failure envelopes in the H-M plane for different soil stiffnesses: (a) $K_{p} \quad 0.01$, (b) $K_{p} \quad 0.001$, (c) $K_{p} \quad 0.0005$, and (d) correlation between the ellipse size $a$ and $K_{p}$.
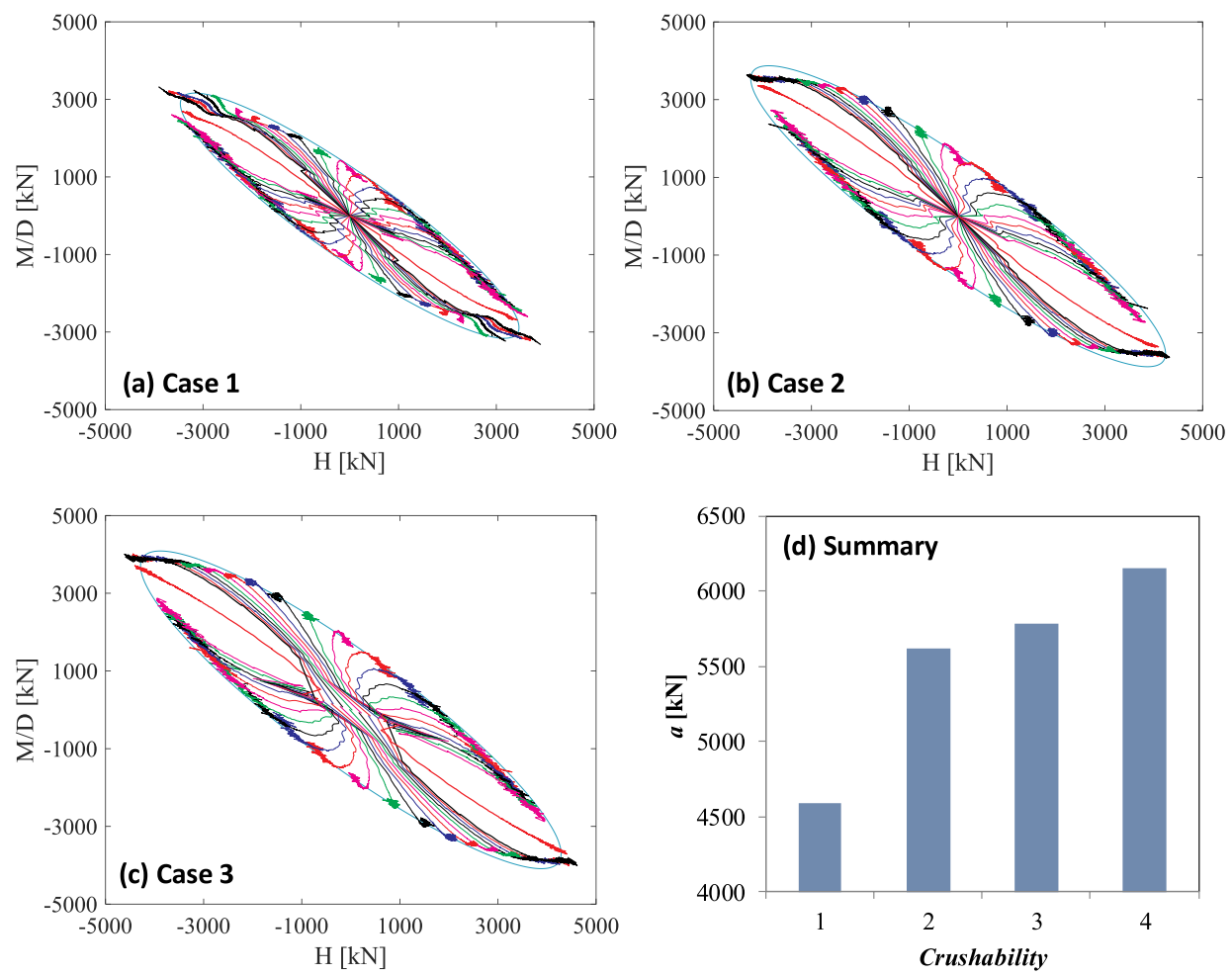

Fig. 21. Failure envelopes in the $H-M$ plane for different sand grain crushabilities: (a) easy crushing, (b) medium crushing, (c) hard crushing, and (d) ellipse size $a$ versus crushability. 
Table 3

Geometry size configurations.

\begin{tabular}{lllllllll}
\hline$L / D$ & 0.5 & $L / D$ & 0.75 & $L / D$ & 1.0 & & $L / D$ & 2.0 \\
\hline 1 & $2 \mathrm{~m}$ & 1.5 & $2 \mathrm{~m}$ & 2 & $2 \mathrm{~m}$ & 2 & $1 \mathrm{~m}$ \\
2 & $4 \mathrm{~m}$ & 3 & $4 \mathrm{~m}$ & 4 & $4 \mathrm{~m}$ & 4 & $2 \mathrm{~m}$ \\
4 & $8 \mathrm{~m}$ & 6 & $8 \mathrm{~m}$ & 8 & $8 \mathrm{~m}$ & 8 & $4 \mathrm{~m}$ \\
8 & $16 \mathrm{~m}$ & 12 & $16 \mathrm{~m}$ & 16 & $16 \mathrm{~m}$ & 16 & $8 \mathrm{~m}$ \\
10 & $20 \mathrm{~m}$ & 15 & $20 \mathrm{~m}$ & 20 & $20 \mathrm{~m}$ & 20 & $10 \mathrm{~m}$ \\
\hline
\end{tabular}

higher ultimate capacity of caisson foundation. The corresponding asymptotic equations are again linear, implying that the bearing capacity of a caisson foundation improves linearly in logarithmic scale with increasing soil friction strength and soil stiffness.

The horizontal and bending moment bearing capacities decrease when considering grain breakage (see Fig. 21). The most significant attenuation occurs for very easily crushable sand (e.g. parameters of Dog's bay sand by Jin et al., 2018a). Finally, it should be noted that the short axis $b$ presents a similar linear trend for different soil properties. On the other hand, the influence of the soil properties on the inclination $\varnothing$ of the bearing capacity diagrams is negligible ( $\varnothing$ remains constant
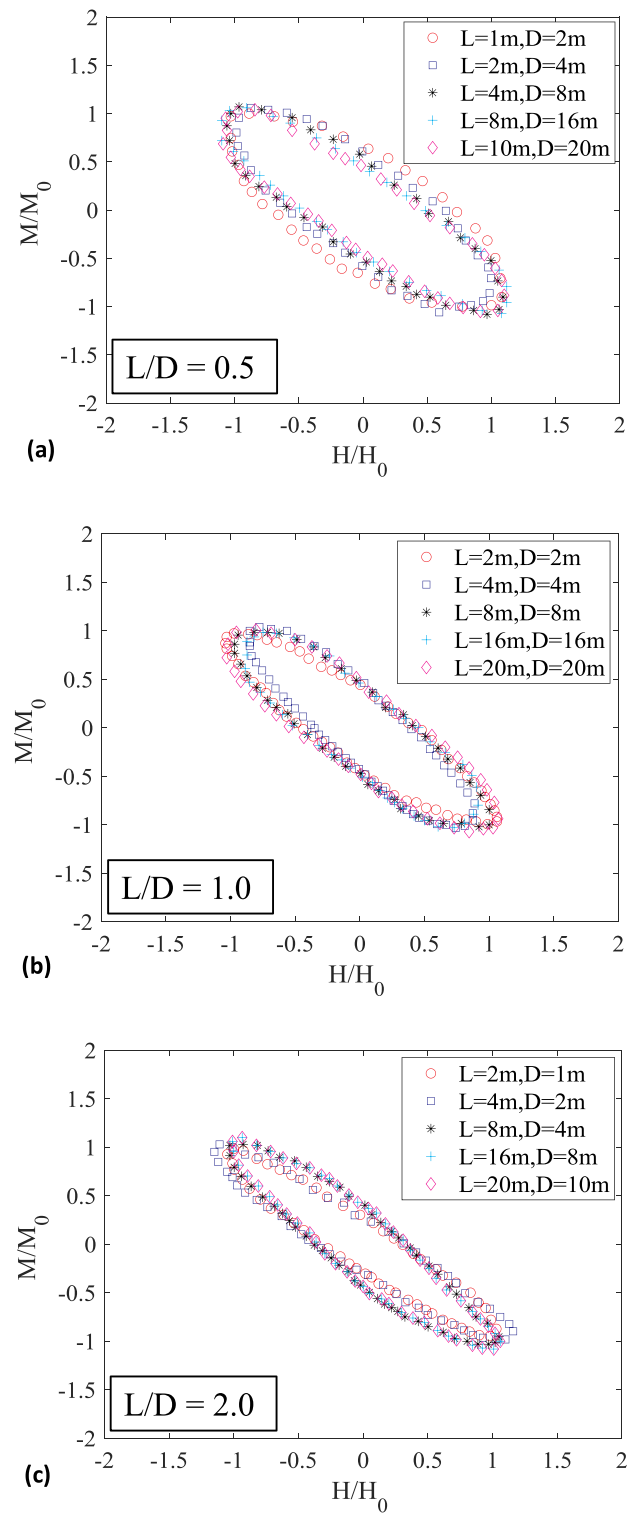

and equal to 42 ).

\subsection{Influence of the caisson foundation size for the same aspect ratio $L / D$}

Previous research works on the failure envelope of caisson foundations mainly focused on model tests on a small scale (Byrne, 2000; Foglia et al., 2015; Houlsby, 2005; Ibsen et al., 2013; Villalobos Jara, 2006). In order to identify the failure envelopes for a full range of caisson sizes, four conventional caisson size aspect ratios $(L / D \quad 0.5,0.75,1.0,2.0)$

Table 4

Geometry size configurations for a constant surface contact area.

\begin{tabular}{|c|c|c|c|c|c|c|c|c|}
\hline \multicolumn{3}{|c|}{ S $\quad 15.7 \mathrm{~m}^{2}$} & \multicolumn{3}{|c|}{ S $\quad 62.8 \mathrm{~m}^{2}$} & \multicolumn{3}{|c|}{ S $\quad 251.3 \mathrm{~m}^{2}$} \\
\hline $\mathrm{L}(\mathrm{m})$ & $\mathrm{D}(\mathrm{m})$ & $\mathrm{L} / \mathrm{D}$ & $\mathrm{L}(\mathrm{m})$ & $\mathrm{D}(\mathrm{m})$ & $\mathrm{L} / \mathrm{D}$ & $\mathrm{L}(\mathrm{m})$ & $\mathrm{D}(\mathrm{m})$ & $\mathrm{L} / \mathrm{D}$ \\
\hline 1 & 2.83 & 0.35 & 2 & 5.8 & 0.34 & 4 & 11.6 & 0.34 \\
\hline 1.5 & 2.31 & 0.65 & 4 & 4 & 1 & 6 & 9.55 & 0.63 \\
\hline 2 & 2 & 1 & 6 & 2.97 & 2.02 & 8 & 8 & 1 \\
\hline 3.56 & 1.5 & 2.37 & 8 & 2.33 & 3.43 & 12 & 5.94 & 2.02 \\
\hline 4.15 & 1.39 & 3 & 10 & 1.91 & 5.23 & 20 & 3.82 & 5.23 \\
\hline
\end{tabular}
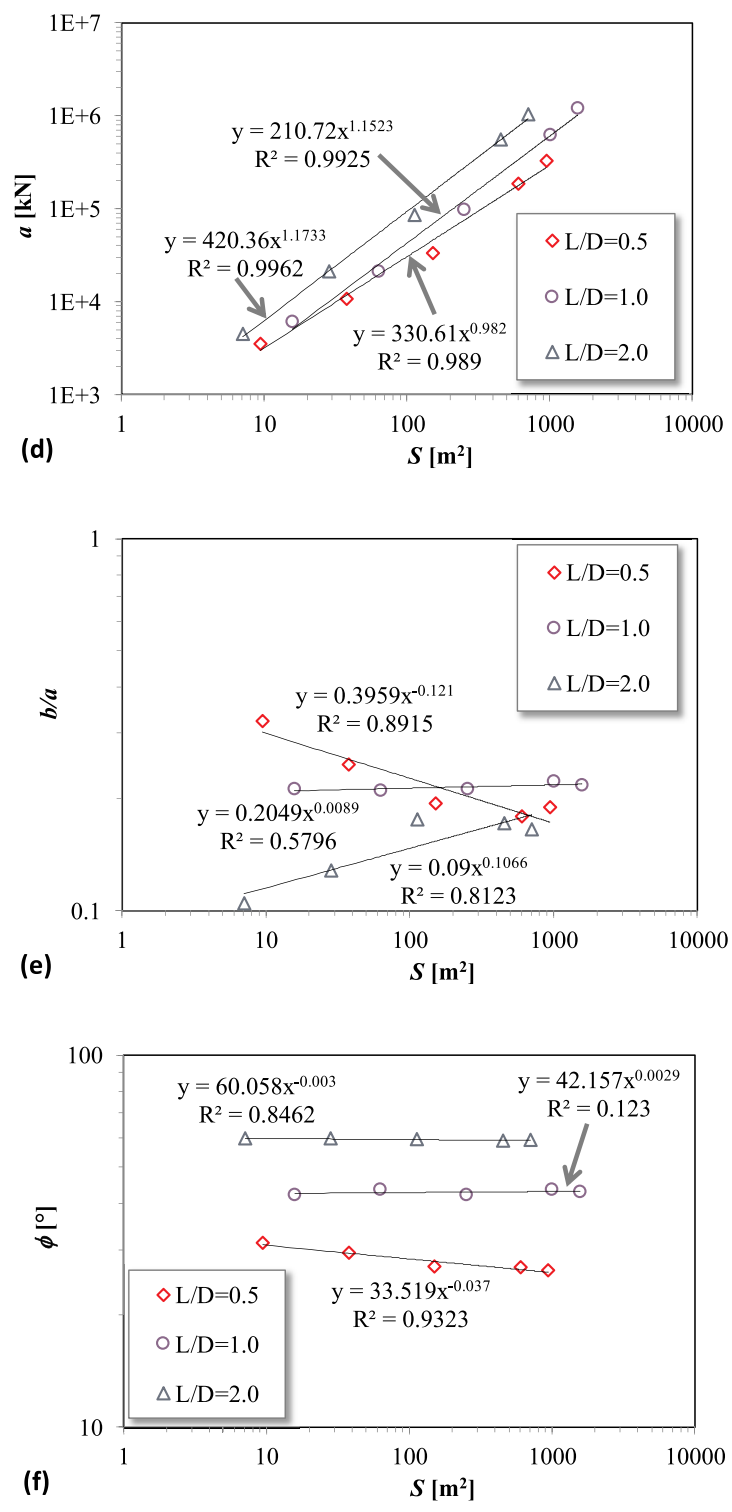

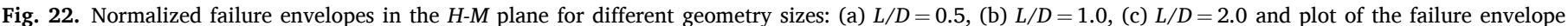
characteristic measures versus the contact surface area $S$ (d) ellipse size $a$, (e) ratio $b / a$, and (f) inclination angle $\varnothing$ 

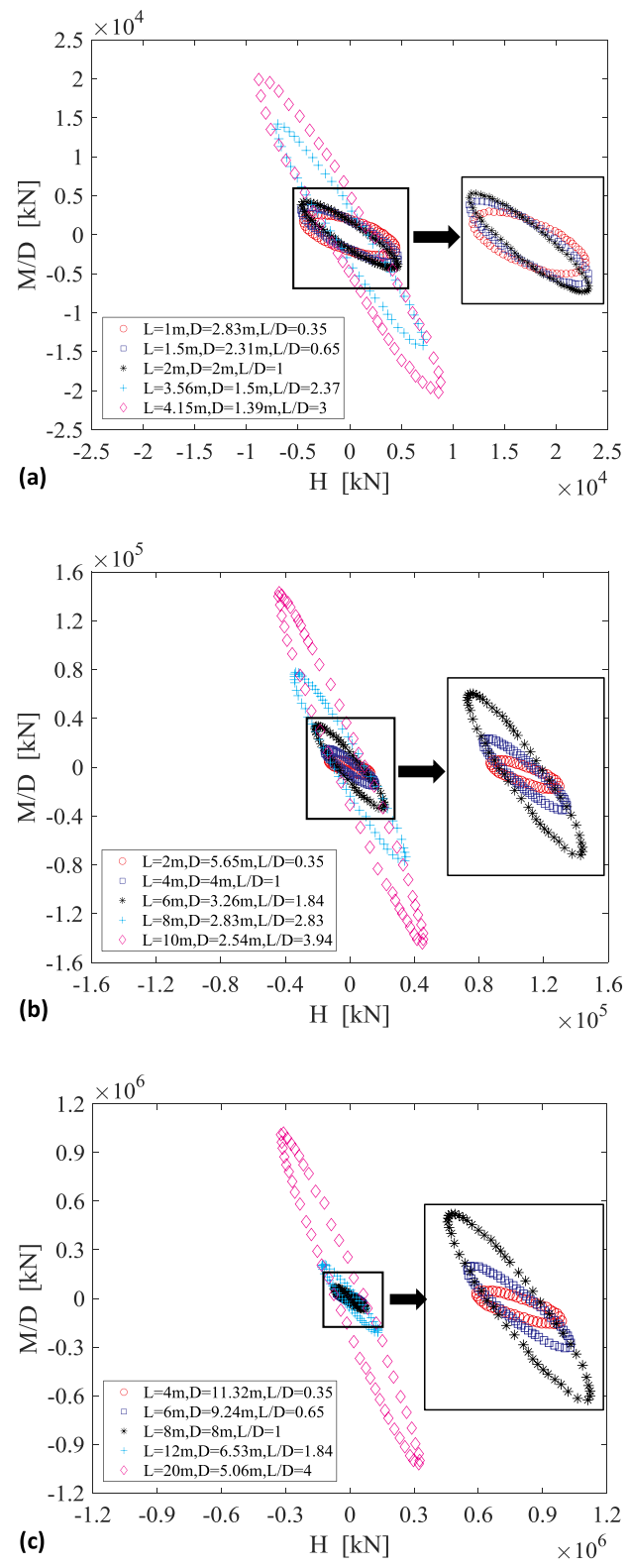
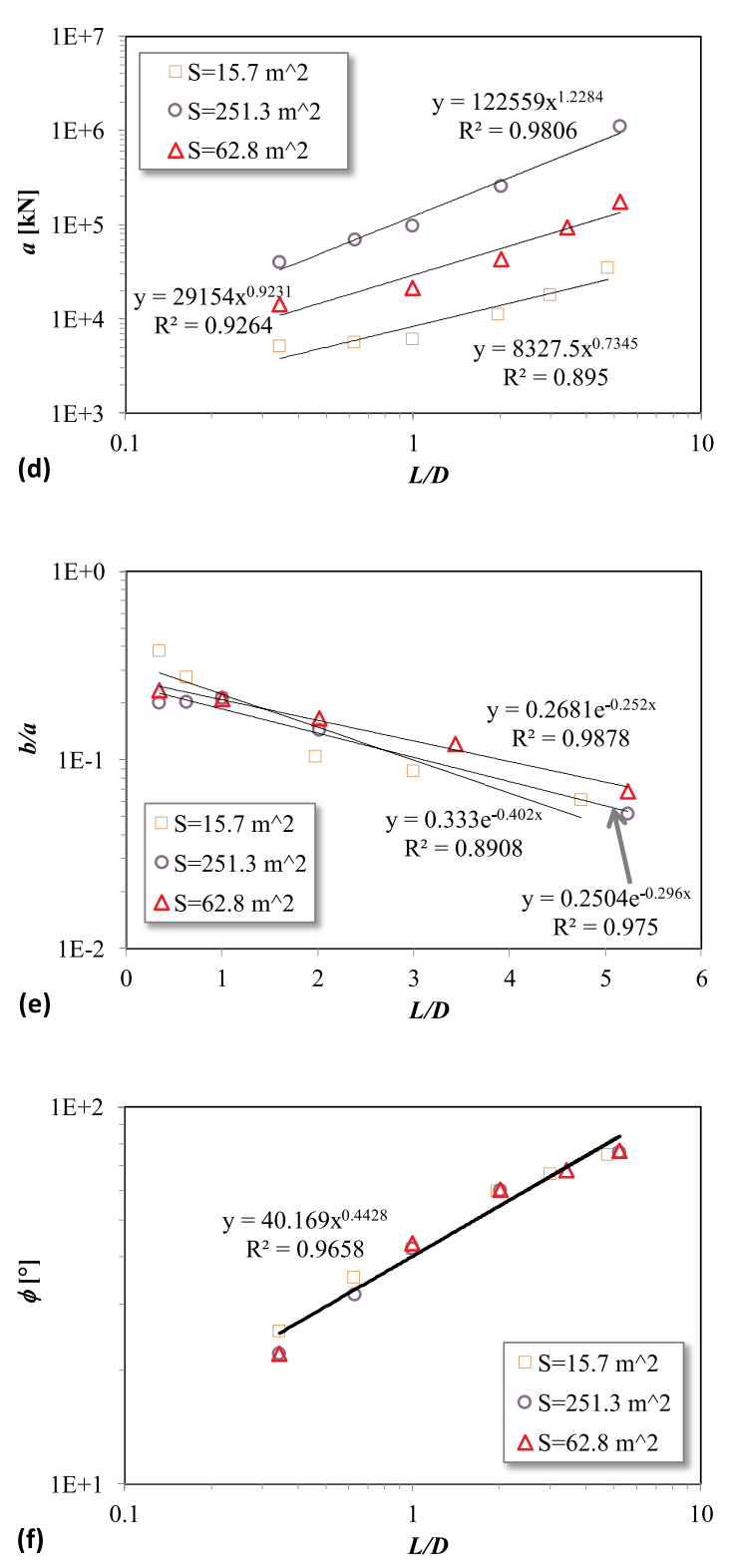

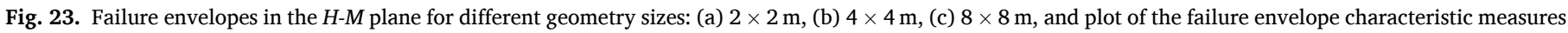
versus the aspect ratio $L / D$ : (d) ellipse size $a$, (e) ratio $b / a$, and (f) inclination angle $\varnothing$

are selected for the simulations presented hereafter. $L$ and $D$ range from $1 \mathrm{~m}$ to $20 \mathrm{~m}$, details are listed in Table 3 . The simulation marked in bold (2 $2 \mathrm{~m}$ ) is the field case simulated in section 3.3.

The failure envelopes for different caisson sizes $L / D$ in the $H-M$ plane are summarized in Fig. 22(a)-(c) (the simulation results of the case $L /$ D 0.75 are presented later on (in section 4.5). As the variations of the horizontal bearing capacity and the bending moment strength are of the order of four to five, a normalized presentation is adopted in the figures. The main results are: (1) For all conventional caisson sizes $L / D$ the failure envelopes present a similar inclined elliptical shape. (2) When L/ $D<1$, the failure envelopes present a slight tendency to contract with increasing caisson size; for $L / D \quad 1$, the failure envelopes are equivalent. When $\mathrm{L} / D>1$, the failure envelopes present a slight tendency to expand. (3) With increasing caisson size $L / D$, the failure envelope exhibits a tendency to contract inward; for the same level of bending moment a smaller horizontal bearing capacity is obtained for larger aspect ratios. Yielding (horizontal) or even failure is more likely to occur on a caisson foundation with a larger aspect ratio. On the contrary and for the same level of horizontal force, a greater bending moment strength occurs for large aspect ratio i.e. an offshore wind turbine with a bigger caisson size aspect ratio has a stronger overturning resistance.

Following a similar analysis, the influence of the caisson size characteristics on the failure envelope is presented in Fig. 22(d)-(f). Here, $S$ is the total contact surface area between the caisson and the soil decomposed in two parts: the surface area of the bottom of the caisson and the surface area of the skirt. The values of the long axis $a$ for different geometric sizes show a linear increase in logarithmic coordinates; the horizontal bearing capacity and overturning resistance are higher with increasing caisson size. For a specified contact surface area the bearing capacity of the caisson improves slightly with increasing aspect ratio, Fig. 22(d). The $b / a$ ratio ( $b$ the short and $a$ the long axis) versus the total contact surface area $S$ is plotted in Fig. 22(e). For increasing caisson sizes, $b / a$ decreases when $L / D<1$, stays constant for $L / D \quad 1$ and increases for $L / D>1$. The inclination angle remains however unchanged, Fig. 22(f). The influence of the caisson size aspect ratios on the inclination of the bearing capacity diagrams is therefore 

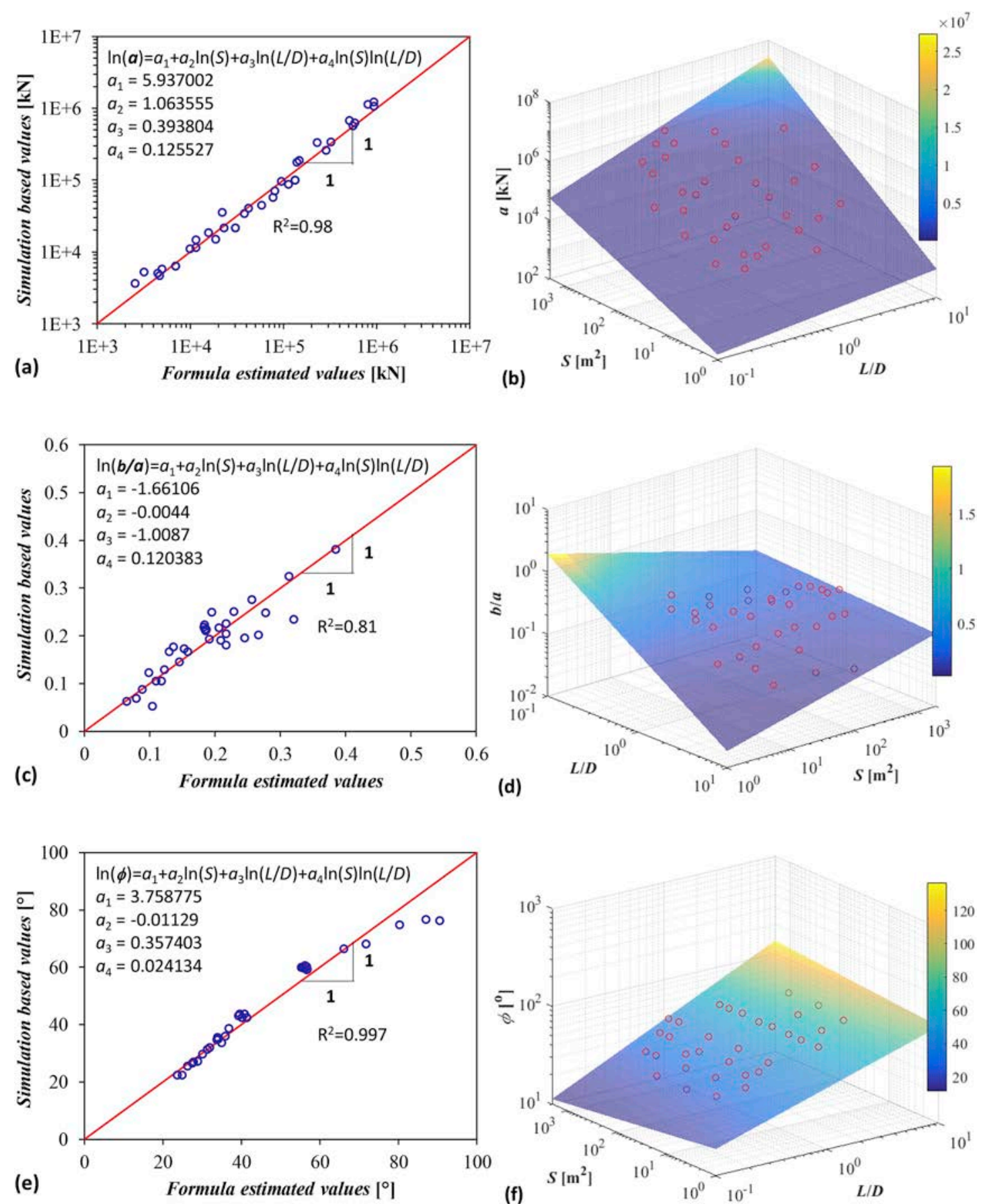

Fig. 24. Comparison between numerically obtained characteristic measures and formula estimated values for: (a) size of ellipse $a$ (b) 3D plot of $a$ versus $S$ and $L / D$, (c) $b / a$ with (d) 3D plot of $b / a$ versus $S$ and $L / D$, and (e) inclination angle $\varnothing$ with (f) 3D plot of $\varnothing$ versus $S$ and $L / D$.

negligible.

4.4. Influence of the aspect ratio $L / D$ for the same soil-structure contact surface area

A number of studies on caisson foundations were carried out to investigate the influence of the aspect ratio $L / D$, experimental (Cassidy et al., 2006; Houlsby et al., 2005; Ibsen et al., 2013, 2015; Tran and Kim, 2017; Zhang et al., 2007; Zhu et al., 2014) and numerical (Cassidy et al., 2006; Cheng et al., 2016; Gerolymos et al., 2012; Li et al., 2015; Liu et al., 2014; Zafeirakos and Gerolymos, 2016). In these studies, the $L$ was changed while $D$ was kept constant (or vice versa) and therefore the contact surface area was different.
In the following, the impact of the aspect ratio $L / D$ on the failure envelope is studied for the same soil-structure contact surface area (implying thus the same cost of construction materials). Three groups of aspect ratio combinations are designed with original geometries equal to $22 \mathrm{~m}, 44 \mathrm{~m}$, and $88 \mathrm{~m}$, details are given in Table 4 . The corresponding numerically simulated failure envelopes are shown in Fig. 23 (a)-(c). Due to the similar sizes, results are not normalized. The main conclusions are: (1) The failure envelopes present different degree inclined elliptical shapes. (2) With increasing $L / D$ ratio, the failure envelope axis rotates clockwise. During the rotation, the envelope gradually retracts along the short axis and stretches along the long axis direction. (3) With increasing $\mathrm{L} / D$ ratio, the bearing capacity gradually transforms from horizontal force dominated failure to bending moment failure. For 


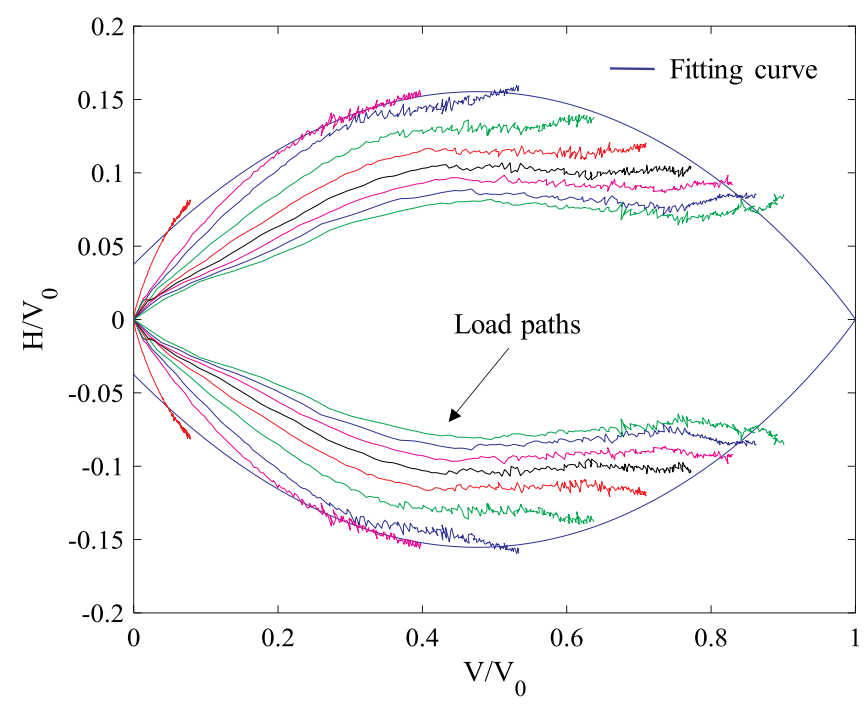

Fig. 25. Numerical results for various load paths and approximate failure envelope in $H$ - $V$ plane.

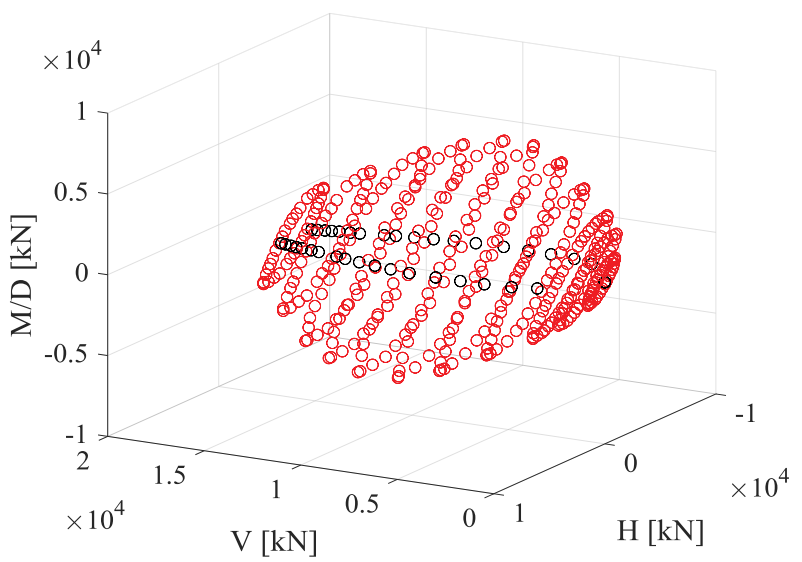

Fig. 26. Failure envelope in the three-dimensional $H-M-V$ space (numerical simulations).

$\mathrm{L} / D<1$, the failure envelopes display a horizontal bearing capacity dominated trend; for $L / D \quad 1$, the bearing horizontal force and bending moment capacities are essentially the same; for $L / D>1$, the bending moment bearing capacity is predominant.

During the design phase of caisson foundations for offshore wind turbines an adequate aspect ratio should be therefore selected according to the actual service environment. The relation between the aspect ratio $L / D$ (for the same soil-structure contact surface area) and the failure envelope is quantified and presented in Fig. 23(d)-(f). It can be seen that $a$ and $\varnothing$ increase with increasing aspect ratio, while in the contrary the ratio $b / a$ decreases.

\subsection{Combined effect of the soil-structure contact surface and the aspect} ratio

In the previous sections, the influence of the caisson foundation size $(L / D)$ and the aspect ratio $L / D$ for the same soil-structure contact surface area on the shape and size of the failure envelope in the $H-M$ space has been presented in details. A formula is proposed hereafter to describe the coupling effect of the soil-structure contact surface area and the aspect ratio on the failure envelope:

$\ln x \quad a_{1} \quad a_{2} \ln S \quad a_{3} \ln L / D \quad a_{4} \ln S \ln L / D$ where $x$ represents the failure envelope characteristic measures $(a, b / a$ and $\varnothing$ ); $S$ is the soil-structure total contact surface area; $L / D$ is the aspect ratio and $a_{1}, a_{2}, a_{3}$ and $a_{4}$ are four constants used for fitting. Based on the previous numerical results (sections 4.3 and 4.4), the four constants are calibrated using the Least-Squares Fitting Method in MATLAB. Fig. 24 displays the comparison between the numerical and the analytical formula estimated values for the three characteristic measures $(a, b / a$ and $\varnothing$ ) of the failure envelope. A strong correlation is observed that proves that the proposed formula is applicable for design purposes and the development of simplified modelling strategies such as the macroelement approach.

\section{Numerical estimation of the $H-M-V$ failure envelope}

\subsection{Influence of $V_{O}$ on the $H-M$ failure envelope}

The horizontal and overturning moment bearing capacities of caisson foundations vary significantly with the vertical load. In order to quantify this effect, a similar procedure as in section 4 is followed hereafter. More specifically, radial displacement numerical simulation tests are carried out for various levels of vertical load. The failure envelopes for different vertical load levels are presented in Fig. 16. The field case shown in Fig. 15 is also added $\left(\begin{array}{ll}\chi & 0.31\end{array}\right)$. It can be concluded that: (1) the influence of the vertical load on the inclination of the bearing capacity diagrams is negligible. (2) the size of the bearing capacity diagram first increases with increasing vertical load and then displays a decreasing trend. This observation agrees with the experimental studies (Villalobos et al., 2009).

\subsection{Numerical failure envelope in the $H-V$ plane}

Numerical radial displacement tests are hereafter performed to identify the failure envelope in the $H-V$ plane. A displacement vector is applied on the LRP of the caisson foundation (see Fig. 13) with an angle varying from $0-180$. The principle of the maximum load (see section 5.1 ) is again adopted to identify the points of the failure locus, see Fig. 25. The obtained failure envelope is similar to the experimental data from Meyerhof (1953), Hansen (1970), DNV (2013) and Ibsen et al. (2014). Due to the high non-linearity the failure points form however an unsmoothed curve. The main results are summarized hereafter: (1) The failure envelopes are symmetric about the $H / V_{O}$ axis. (2) A strong interaction is observed between the vertical and the horizontal loads. The horizontal bearing capacity first increases and then decreases. As shown in Fig. 25, a peak value is obtained for a vertical load equal to $0.4-0.5$ of the vertical bearing capacity. This agrees with Fig. 16 on the $H-M$ plane. It can be also observed that the horizontal force is non-zero for null vertical loading because of the existence of the skirt.

\subsection{Numerical failure envelope in the $H-M-V 3 D$ space}

By combining the results in the $H-M$ plane for different vertical levels (Figs. 15 (b) and Fig. 16) and in the $H-V$ plane (Fig. 25), the $H-M-V$ 3D space envelope is plotted in Fig. 26. It has inclined elliptical crosssections along the vertical force axis and its size is controlled by the value of the vertical load.

\subsection{Influence of the soil properties and the caisson dimensions}

The influence of the soil relative density $D_{r}$, the soil stiffness $k_{p}$, the friction angle $\varphi_{c}$, the grain breakage and the caisson dimensions (soilstructure contact surface area, aspect ratio) on the vertical bearing capacity $V_{0}$ are studied hereafter.

A strong linear tendency can be observed between $V_{O}$ and $D_{r}, \varphi_{c}$ and $k_{p}$, see Fig. 27 . The vertical bearing capacity decreases for higher sand crushability. The most significant attenuation occurred with the Dog's 

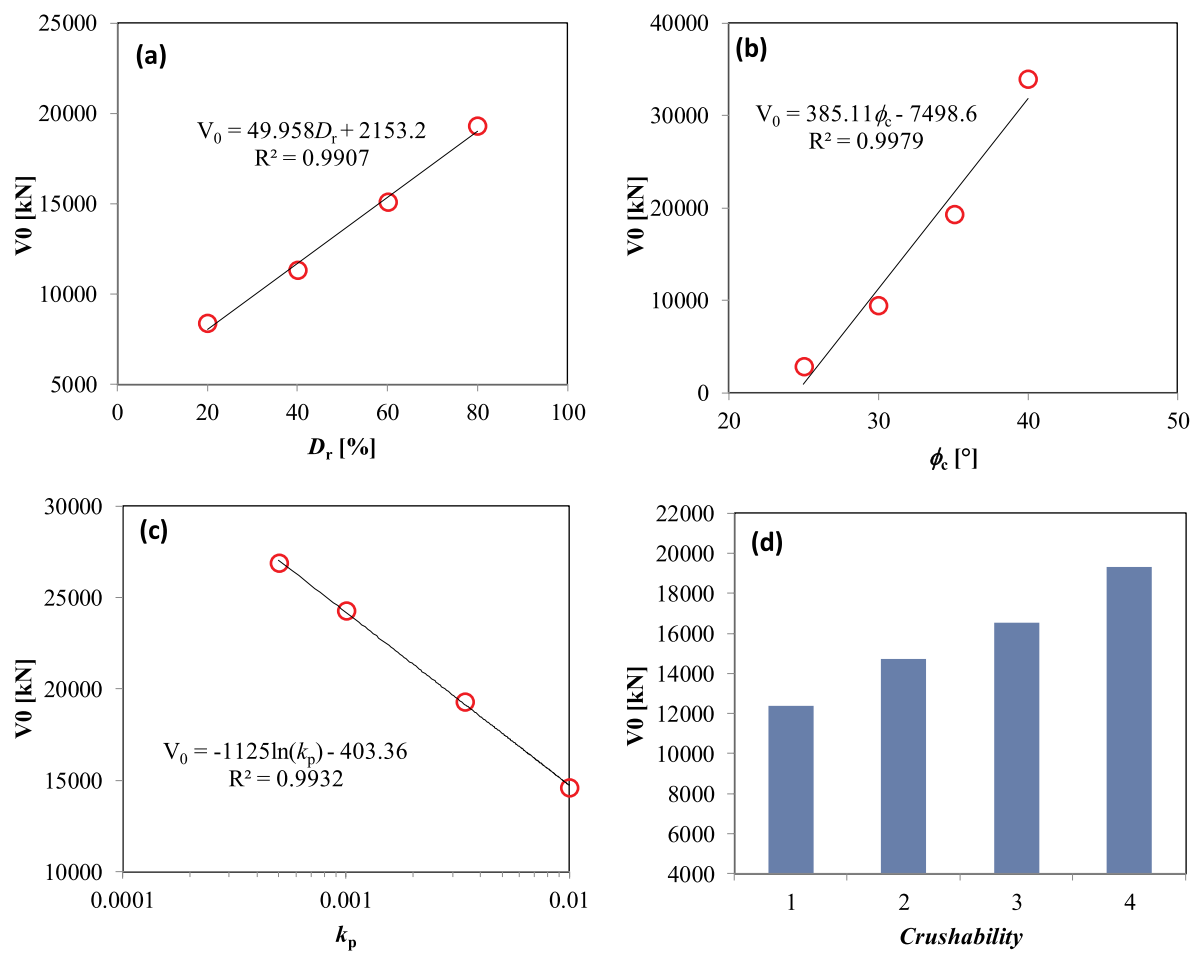

Fig. 27. Relationship between vertical bearing capacity $V_{O}$ and related soil properties: (a) relative density, (b) critical friction angle, (c) plastic stiffness and (d) sand grain crushability.

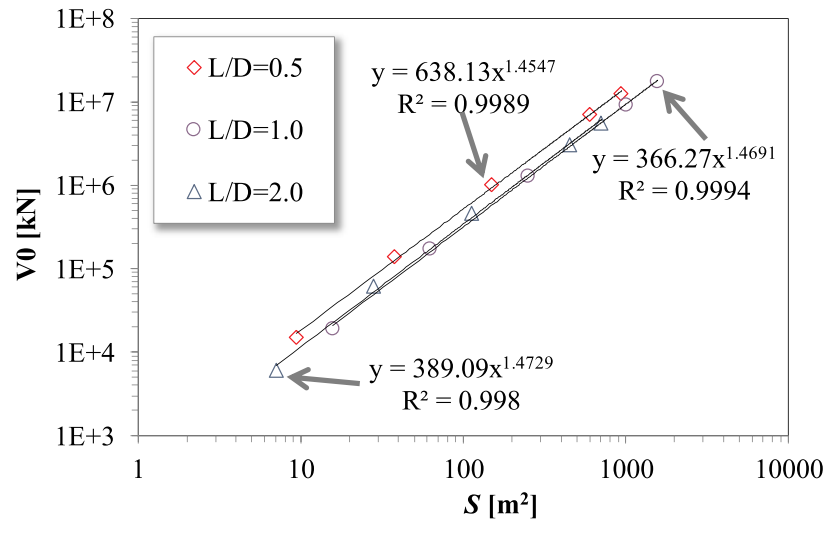

Fig. 28. Vertical bearing capacity $V_{0}$ versus contact surface area $S$ for different aspect ratios $L / D$.

bay sand, which is the most crushable sand.

The influence of the caisson foundation geometry on $V_{0}$ is presented in Table 3 (a similar simulation configuration as in section 4.3 is made). Fig. 28 displays the relation between the vertical bearing capacity and the soil-structure contact surface area for three conventional aspect ratios. $V_{O}$ and $S$ present a linear relation in logarithmic coordinates. It is worth noting that for different aspect ratios, the vertical peak-bearing capacity is found the same for similar contact surface areas. In other words, the vertical bearing capacity is mainly controlled by the contact surface area between the soil and the caisson, regardless of the aspect ratio.

To estimate the influence of the aspect ratio, the same soil-structure contact surface is maintained while simultaneously changing the values of $L$ and $D$. The relation between the aspect ratio and the vertical bearing capacity for three geometry levels is shown in Fig. 29. $V_{O}$ and $L / D$

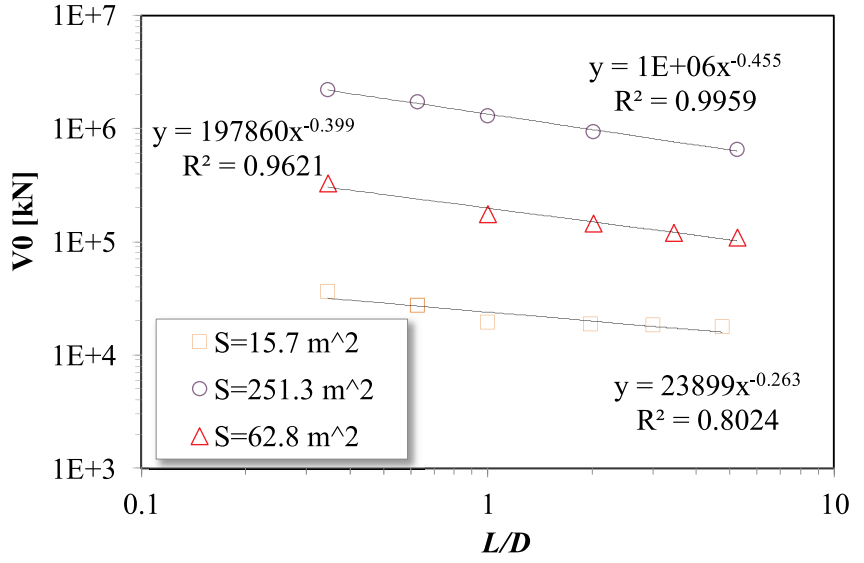

Fig. 29. Vertical bearing capacity $V_{O}$ versus aspect ratio $L / D$.

present a linear negative correlation in logarithmic coordinates; for the same surface contact area a bigger $L / D$ implies smaller contact area between the bottom of the caisson and the soil. Furthermore, for the same aspect ratio the vertical bearing capacity increases with an increase in the caisson's geometry because of the contact area increase at the bottom of the caisson.

The same analytical equation as in section 4.5 is adopted to describe the coupling between geometry, aspect ratio and vertical bearing capacity. Fig. 30 illustrates the comparison between the simulation-based values and the formula-estimated values for a given vertical bearing capacity. The proposed analytical formula successfully reproduces the simulation results.

As presented and discussed above, a large number of simulations were carried out to investigate the behaviour of a caisson foundation subjected to different load combinations in this study. The average computation time for each case approximately equals to $8 \mathrm{~h}$ by adopting 

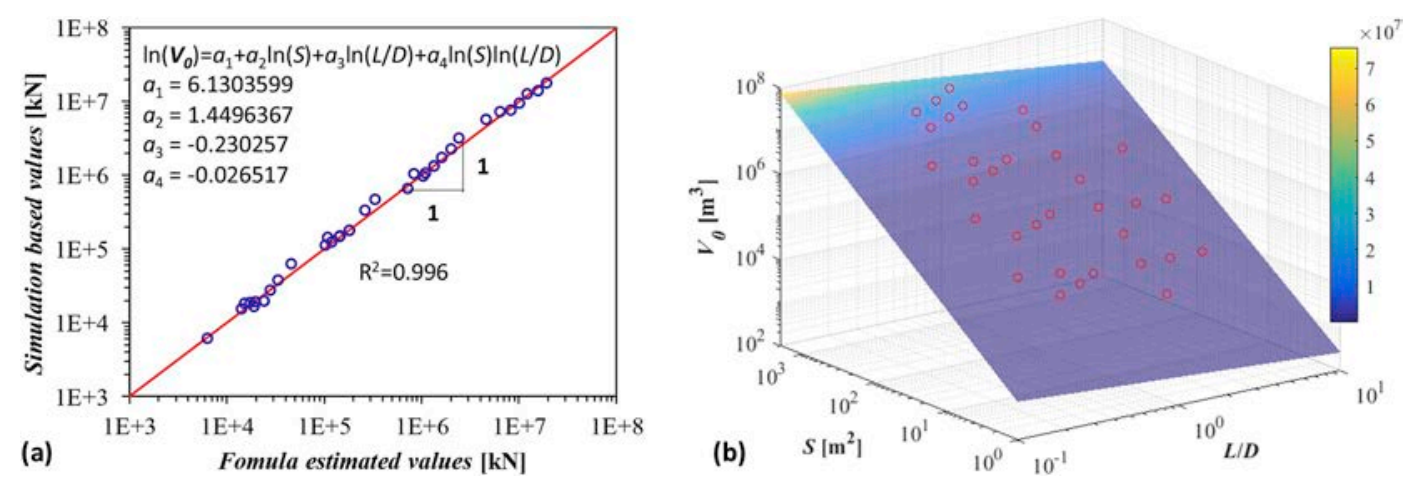

Fig. 30. (a) Comparison between the vertical bearing capacity $V_{0}$ and the formula estimated $V_{0}$, and (b) 3D plot of the correlation between $V_{0}$, the contact surface area $S$ and the aspect ratio $L / D$.

Table 5

Intersection and eccentricity parameters: $h_{i}, m_{i}$ and $e$.

\begin{tabular}{|c|c|c|c|c|c|c|c|c|c|}
\hline$L(\mathrm{~m})$ & $D(\mathrm{~m})$ & $\mathrm{L} / \mathrm{D}$ & $\mathrm{V} / \mathrm{V}_{0}$ & $\mathrm{a}$ & $\mathrm{b}$ & $\varnothing()$ & $\mathrm{h}_{\mathrm{i}}$ & $\mathrm{m}_{\mathrm{i}}$ & $\mathrm{e}$ \\
\hline 1 & 2.83 & 0.35 & 0.18 & 4793 & 1820 & 25.4 & 0.1005 & 0.0601 & 0.657 \\
\hline 1.5 & 2.31 & 0.65 & 0.26 & 5655 & 1518 & 36.4 & 0.1054 & 0.0808 & 0.871 \\
\hline 2 & 2 & 1 & 0.31 & 6155 & 1308 & 42.1 & 0.0982 & 0.0896 & 0.913 \\
\hline 3.56 & 1.5 & 2.37 & 0.26 & 15855 & 1557 & 63.9 & 0.0760 & 0.1521 & 0.970 \\
\hline 4.15 & 1.39 & 3 & 0.28 & 21546 & 1878 & 66.3 & 0.0962 & 0.2151 & 0.973 \\
\hline
\end{tabular}
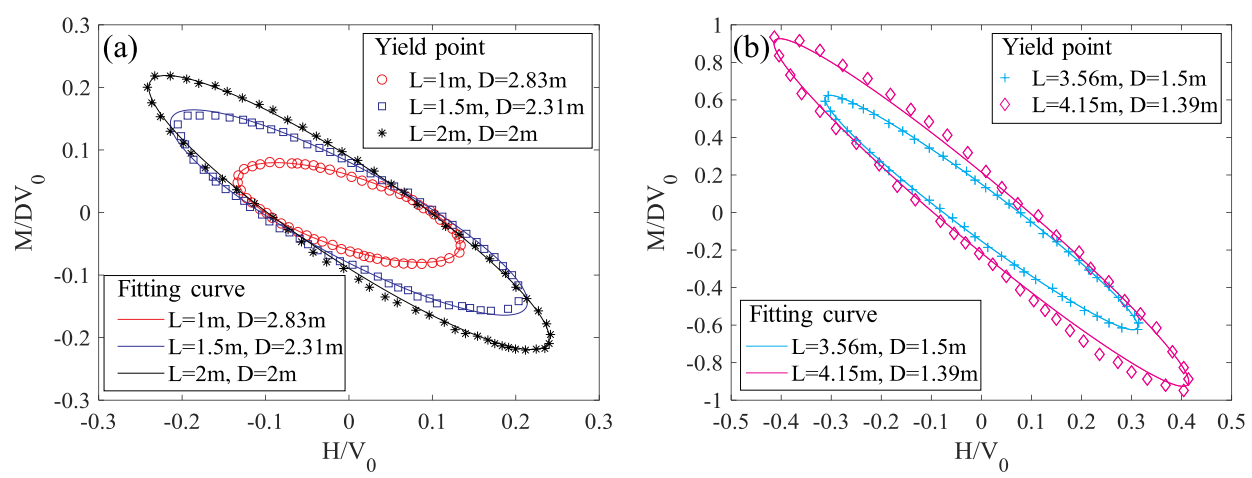

Fig. 31. Comparison of fitted curves by the analytical equation and numerical results for different aspect ratios: (a) $L / D \quad 0.35,0.65$ and 1 , (b) $L / D \quad 2.37$ and 3 .

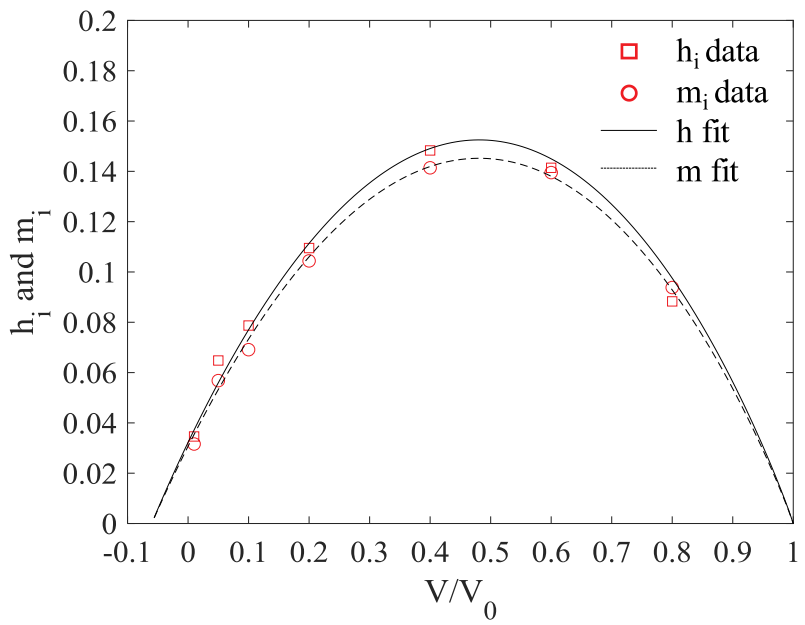

Fig. 32. Intersection points $h_{i}$ and $m_{i}$ as a function of the normalized vertical load $V / V_{0}$. eight cores (processor clock speed equals to $2.50 \mathrm{GHz}$ ). Note that several cases can been submitted and calculated simultaneously owing to the LIGER server and related computation resources provided by ECN (Ecole Centrale de Nantes, France), the method and number of simulations are acceptable.

\section{Analytical equations for the failure envelope}

\subsection{Analytical equations for the failure envelope in the H-M plane}

As shown in Section 4.1, the failure envelope in the $H-M$ plane has an inclined elliptical shape. Following Villalobos et al. (2009), a similar formula is introduced to reproduce the inclined failure envelope of a caisson foundation in sand:

$y \quad{\frac{H}{h_{i} V_{0}}}^{2} \quad{\frac{M}{D m_{i} V_{0}}}^{2} \quad 2 e \frac{H}{h_{i} V_{0}} \frac{M}{D m_{i} V_{0}} \quad 1 \quad 0$

The general shape of the surface is determined by the parameters $h_{i}$, $m_{i}$, and $e$. The fitting parameters $h_{i}$ and $m_{i}$ represent the intersection of each ellipse with the $H / V_{0}$ and $M / D V_{O}$ axes respectively, $e$ being the eccentricity of each ellipse. Using this equation, the yield points simulated in the previous sections can be fitted using a least-squares regression. 


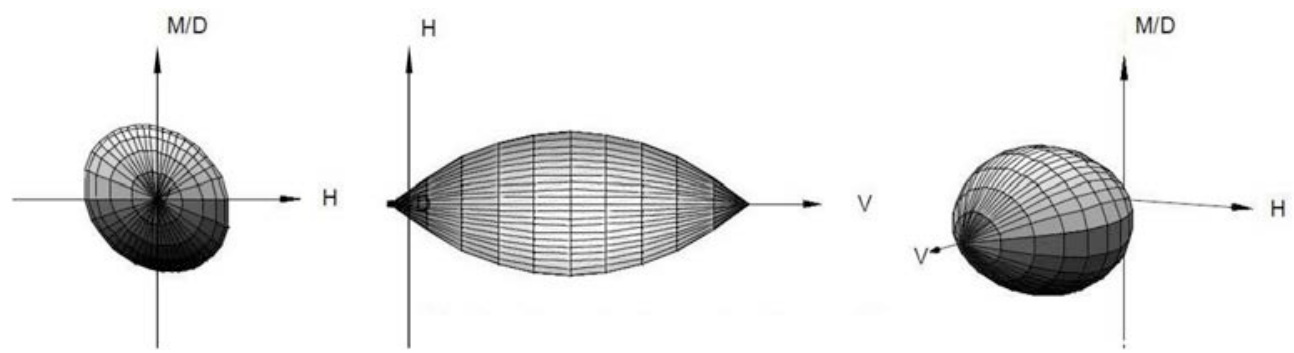

Fig. 33. Illustration of the yield surface shaped as a parabola and inclined ellipse in the $(V, M / D, H)$ load space.

Table 6

Parameters of the proposed failure surface for the $22 \mathrm{~m}$ caisson foundation.

\begin{tabular}{lll}
\hline Parameter & Name & Value \\
\hline$V_{0}$ & Vertical bearing capacity: kN & 19330 \\
$t_{0}$ & Tension factor & 0.06 \\
$e$ & Eccentricity of yield surface & 0.913 \\
$h_{0}$ & Dimension of yield surface (horizontal) & 0.145 \\
$m_{0}$ & Dimension of yield surface (moment) & 0.138 \\
$\beta_{1}$ & Shaping factor of yield surface & 0.99 \\
$\beta_{2}$ & Shaping factor of yield surface & 0.95 \\
\hline
\end{tabular}

Eq. (5) satisfies the implicit equation of an ellipse, also referred to as the general equation:

$A_{1} X^{2} \quad A_{2} X Y \quad A_{3} Y^{2} \quad A_{4} X \quad A_{5} Y \quad A_{6} \quad 0$

(6)

The general equation's coefficients can be obtained from the semimajor axis $a$, the semi-minor axis $b$, the centre coordinates $\left(x_{c}, y_{c}\right)$ and the rotation angle $\varnothing$ of the failure envelope using the following formulae:

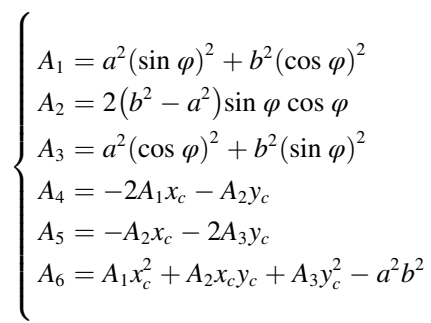

The centre coordinates of the failure envelope in the $H-M$ plane coincide with the origin. $A_{4}, A_{5}$ and $A_{6}$ therefore become:

$\begin{cases}A_{4} & 0 \\ A_{5} & 0 \\ A_{6} & a^{2} b^{2}\end{cases}$

Here, only three parameters, $a, b$ and $\varnothing$ describe the shape and size of the
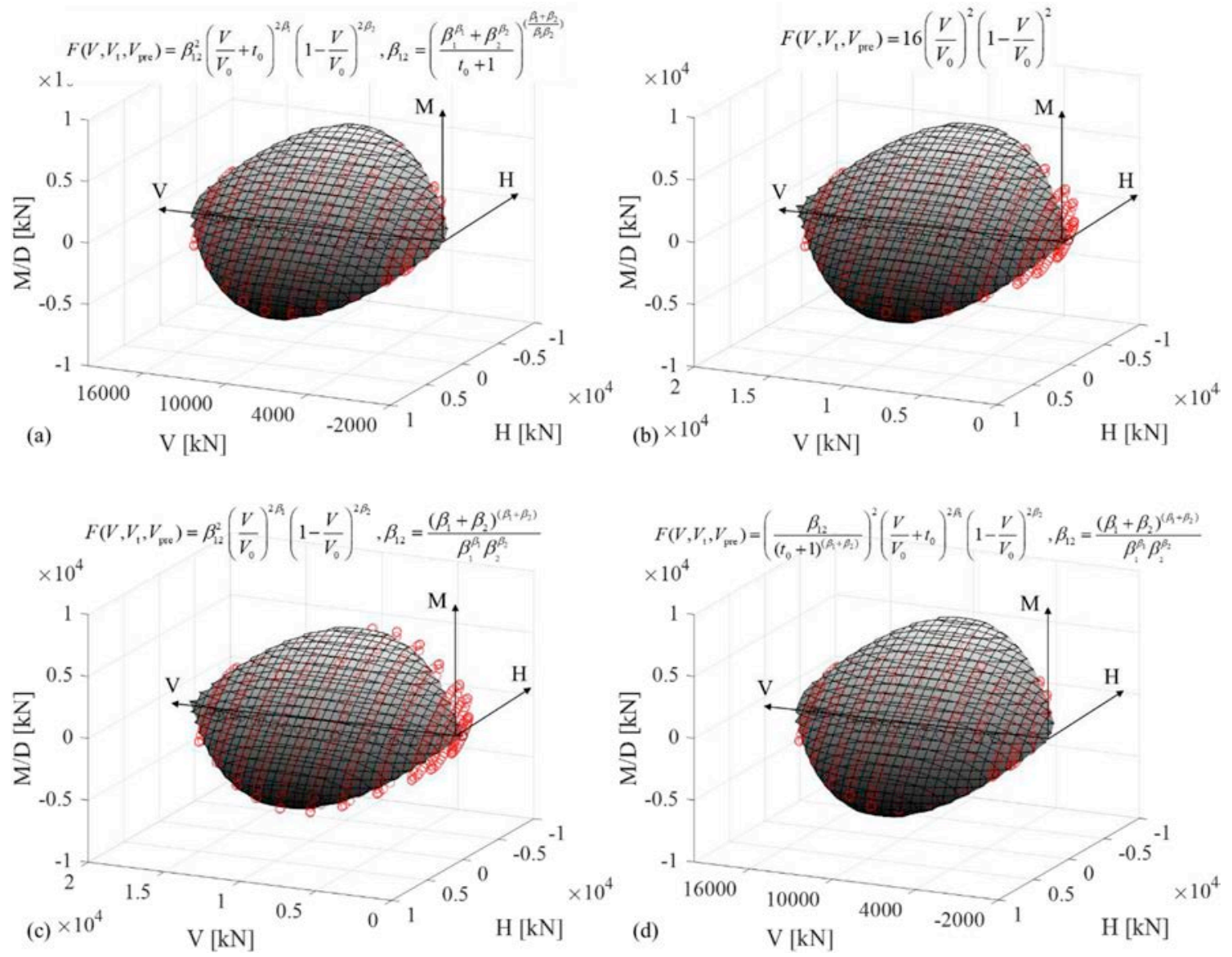

Fig. 34. Numerical yield points fitted by the three-dimensional failure envelopes based on (a) Eq. (12), (b) Gottardi et al. (1999), (c) Byrne and Houlsby (1999) and (d) Villalobos et al. (2009). 
failure envelope in the $H-M$ plane. By comparing Eq. (5) and Eq. (6), $h_{i}$, $m_{i}$ and $e$ are expressed as follows:

$$
\left\{\begin{array}{l}
h_{i} \frac{a b}{V_{0} \sqrt{a^{2} \sin ^{2} \varphi \quad b^{2} \cos ^{2} \varphi}} \\
m_{i} \frac{a b}{V_{0} \sqrt{a^{2} \cos ^{2} \varphi \quad b^{2} \sin ^{2} \varphi}} \\
e \frac{\sin \varphi \cos \varphi a^{2}}{b^{2}} \\
\sqrt{a^{2} \sin ^{2} \varphi \quad b^{2} \cos ^{2} \varphi a^{2} \cos ^{2} \varphi \quad b^{2} \sin ^{2} \varphi}
\end{array}\right.
$$

It must be pointed out that the values of $a$ and $b$ are related to the current vertical loading level $\chi$. The coupling relationships among the characteristic measures of the failure envelope, soil-structure contact surface area and aspect ratio have been comprehensively analysed and quantified through Eq. (4). For a given caisson geometry, the failure envelope in the $H-M$ space for a given soil can be therefore obtained using Eq. (4), Eq. (5) and Eq. (9).

Using Eq. (9), the fitted parameters $h_{i}, m_{i}$ and $e$ of the first group of aspect ratio combinations studied in section 4.4 are displayed in Table 5 , in which the original geometry (field test) equals $2 \quad 2 \mathrm{~m}$. Fig. 31 shows the comparison of Eq. (5) with the numerical results for the normalized failure envelope in the $H-M$ plane. It is observed that the proposed equation fits well the different yield points.

\subsection{Analytical equations for the failure envelope in the $H-M-V 3 D$ space}

Fig. 32 shows how $h_{\mathrm{i}}$ and $m_{\mathrm{i}}$ vary with the normalized load $V / V_{0}$. It can be seen that the apex of the yield surface at low vertical loads is not at the origin but at a negative value because of the tension capacity of the caisson foundation. The tension capacity needs to be considered in order to obtain a more reasonable expression for the 3D yield surface.

The proposed formula is similar to that proposed by Villalobos et al. (2009) but in a more concise form.

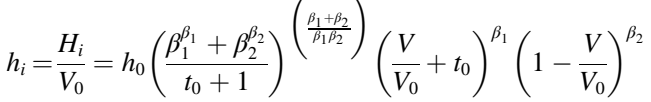

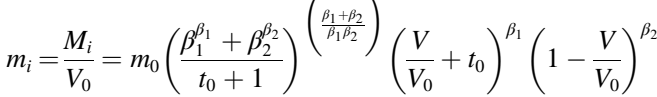

The two parameters $\beta_{1}$ and $\beta_{2}$ are shaping parameters that allow to best fit the data and are generally close to unity (lager values will make the failure envelope concave (Ibsen et al., 2013)). $h_{0}$ and $m_{0}$ are the maximum values of $h_{i}$ and $m_{i}$ over the full range of $V / V_{0} . t_{0}$ controls the tension loading that the caisson foundation can sustain. It can be obtained by using a function of the skirt thickness $t$ relative to the diameter of the caisson (Villalobos et al., 2004, 2005).

Eqs. (5), (10) and (11) can be combined to represent an inclined parabolic ellipsoid in the 3D $H-M-V$ plane as follows:

$$
y \quad{\frac{H}{h_{0} V_{0}}}^{2} \quad \frac{M}{D m_{0} V_{0}}{ }^{2} \quad 2 e \frac{H}{h_{0} V_{0}} \frac{M}{D m_{0} V_{0}} \quad F V, V_{t}, V_{0} \quad 0
$$

Where

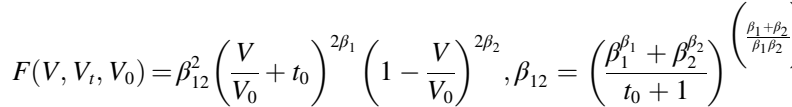

Here $V_{\mathrm{t}}$ is the tension capacity of the caisson foundation. An example of the complete three-dimensional shape of the rotated yield surface is shown in Fig. 33.

The parameters obtained from the best curve fitting with the numerical results are presented in Table 6 . The 3D failure envelope for a caisson foundation in sand according to Eq. (12) is plotted in Fig. 34(a). The expressions proposed by Gottardi et al. (1999), Byrne and Houlsby (1999) and Villalobos et al. (2009) are also plotted in Fig. 34(b), (c) and $34(d)$. The correlation factor $R^{2}$ is estimated as $0.88,0.67,0.79$ and 0.82 , respectively indicating that Eq. (12) is more suitable to reproduce the 3D failure envelope of the caisson foundation.

\section{Conclusions}

A numerical study combining the Lagrangian-SPH method (CLSPH) and the elastoplasticity constitutive law SIMSAND is presented to identify the failure envelope of caisson foundation in sand. The soil parameters of the SIMSAND model were first calibrated from a series of triaxial tests on Baskarp sand. A simulation of a cone penetration test was then conducted to validate the CLSPH-SIMSAND modelling strategy. A series of model tests and a field test of a caisson foundation were also selected and simulated. Results demonstrated that the CLSPHSIMSAND approach was able to reproduce the response of caisson foundation in sand with the calibrated soil parameters.

Then, a large number of finite element numerical calculations were carried out to investigate the behaviour of a caisson foundation subjected to different load combinations. The radial displacement method was adopted for the simulations. A series of factors including the soil density, friction strength, soil stiffness, grain crushability, the caisson geometry and aspect ratio, were considered to study the failure envelope. Finally, an analytical formula was proposed to describe the 3D failure envelope in the $H-M-V$ space that can be used for the design and the development of simplified modelling strategies as the macroelement approach.

\section{Acknowledgements}

This research was financially supported by a RIF project (Grant No.: PolyU R5037-18F) and a GRF project (Grant No.: 15209119) from Research Grants Council (RGC) of Hong Kong Special Administrative Region Government (HKSARG) of China, and the National Natural Science Foundation of China (Grant No. 51579179).

\section{References}

Abaqus, I., 2014. Abaqus Documentation. Dassault Systemes Simulia Corp., Providence, RI, USA. Version 6, 5-1.

Achmus, M., Akdag, C.T., Thieken, K., 2013. Load-bearing behavior of suction bucket foundations in sand. Appl. Ocean Res. 43, 157-165.

Bojanowski, C., 2014. Numerical modeling of large deformations in soil structure interaction problems using FE, EFG, SPH, and MM-ALE formulations. Arch. Appl. Mech. 84, 743-755.

Byrne, B., Houlsby, G., 1999. Drained Behaviour of Suction Caisson Foundations on Very Dense Sand, Offshore Technology Conference. Offshore Technology Conference, Houston paper 10994.

Byrne, B., Houlsby, G., 2001. Observations of footing behaviour on loose carbonate sands. Geotechnique 51 (5), 463-466.

Byrne, B.W., 2000. Investigations of Suction Caissons in Dense Sand. University of Oxford, Oxford, UK.

Cassidy, M., Byrne, B., Houlsby, G., 2002. Modelling the behaviour of circular footings under combined loading on loose carbonate sand. Geotechnique 52 (10), 705-712.

Cassidy, M., Randolph, M., Byrne, B., 2006. A plasticity model describing caisson behaviour in clay. Appl. Ocean Res. 28 (5), 345-358.

Chen, W., Qiu, T., 2012. Numerical simulations for large deformation of granular materials using smoothed particle hydrodynamics method. Int. J. Geomech. 12, $127-135$.

Cheng, X., Wang, J., Wang, Z., 2016. Incremental elastoplastic FEM for simulating the deformation process of suction caissons subjected to cyclic loads in soft clays. Appl. Ocean Res. 59, 274-285.

Cremer, C., Pecker, A., Davenne, L., 2001. Cyclic macro-element for soil-structure interaction: material and geometrical non-linearities. Int. J. Numer. Anal. Methods Geomech. 25 (13), 1257-1284.

DNV, D.N.V., 2013. Design of Offshore Wind Turbine Structures. Standard DNV-Osj101, Det Norske Veritas AS (DNV).

Foglia, A., Gottardi, G., Govoni, L., Ibsen, L.B., 2015. Modelling the drained response of bucket foundations for offshore wind turbines under general monotonic and cyclic loading. Appl. Ocean Res. 52, 80-91. 
Gerolymos, N., Zafeirakos, A., Karapiperis, K., 2015. Generalized failure envelope for caisson foundations in cohesive soil: static and dynamic loading. Soil Dyn. Earthq. Eng. 78, 154-174.

Gerolymos, N., Zafeirakos, A., Souliotis, C., 2012. Insight to failure mechanisms of caisson foundations under combined loading: a macro-element approach. In: Proc. 2nd Int. Conf. On Performance-Based Design in Earthquake Geotechnical Engineering. Taormina, Italy.

Gingold, R.A., Monaghan, J.J., 1977. Smoothed particle hydrodynamics: theory and application to non-spherical stars. Mon. Not. R. Astron. Soc. 181 (3), 375-389.

Gottardi, G., Butterfield, R., 1993. On the bearing capacity of surface footings on sand under general planar loads. Soils Found. 33 (3), 68-79.

Gottardi, G., Houlsby, G., Butterfield, R., 1999. Plastic response of circular footings on sand under general planar loading. Geotechnique 49 (4), 453-470.

Gourvenec, S., Barnett, S., 2011. Undrained failure envelope for skirted foundations under general loading. Geotechnique 61 (3), 263-270.

Gourvenec, S., Randolph, M., 2003. Effect of strength non-homogeneity on the shape of failure envelopes for combined loading of strip and circular foundations on clay. Geotechnique 53 (6), 575-586.

Grange, S., Kotronis, P., Mazars, J., 2008. A macro-element for a circular foundation to simulate 3D soil-structure interaction. Int. J. Numer. Anal. Methods Geomech. 32 (10), 1205-1227.

Hansen, J.B., 1970. A Revised and Extended Formula for Bearing Capacity, vol. 28. Danish Geotechnical Institute, pp. 5-11. Bulletin No.

Hibbitt, Karlsson, Sorensen, 2001. ABAQUS/Explicit: User's Manual. Hibbitt, Karlsson and Sorenson Incorporated.

Hogervorst, J.R., 1980. Field trails with large diameter suction piles, Offshore Technology Conference. Offshore Technol. Conf. Paper. OTC 3817.

Houlsby, G., 2005. The Theoretical Modelling of Circular Shallow Foundation for Offshore Wind Turbines. University of, Oxford.

Houlsby, G., Cassidy, M., 2002. A plasticity model for the behaviour of footings on sand under combined loading. Geotechnique 52 (2), 117-129.

Houlsby, G.T., Ibsen, L.B., Byrne, B.W., 2005. Suction Caissons for Wind Turbines. Frontiers in Offshore Geotechnics. ISFOG, Perth, WA, Australia, pp. 75-93.

Houlsby, G.T., Kelly, R.B., Huxtable, J., Byrne, B.W., 2006. Field trials of suction caissons in sand for offshore wind turbine foundations. Geotechnique 56, 3-10.

Ibsen, L.B., Barari, A., Larsen, K.A., 2013. Adaptive plasticity model for bucket foundations. J. Eng. Mech. 140 (2), 361-373.

Ibsen, L.B., Barari, A., Larsen, K.A., 2015. Effect of embedment on the plastic behavior of bucket foundations. J. Waterw. Port, Coast. Ocean Eng. 141, 1-9.

Ibsen, L.B., Larsen, K.a., Barari, a., 2014. Calibration of failure criteria for bucket foundations on drained sand under general loading. J. Geotech. Geoenviron. Eng. 140,04014033

Ibsen, L.B., Liingaard, S., Nielsen, S.A., 2005. Bucket foundation, a status. In: Proceedings of the Copenhagen Offshore Wind, 26-28 Octorber, Copenhagen, Denmark.

Iskander, M., El-Gharbawy, S., Olson, R., 2002. Performance of suction caissons in sand and clay. Can. Geotech. J. 39, 576-584.

Jin, Y.-F., Wu, Z.-X., Yin, Z.-Y., Shen, J.S., 2017. Estimation of critical state-related formula in advanced constitutive modeling of granular material. Acta Geotechnica $1-23$.

Jin, Y.-F., Yin, Z.-Y., Shen, S.-L., Hicher, P.-Y., 2016. Investigation into MOGA for identifying parameters of a critical-state-based sand model and parameters correlation by factor analysis. Acta Geotechnica 11 (5), 1131-1145.

Jin, Y.-F., Yin, Z.-Y., Shen, S.-L., Hicher, P.-Y., 2016. Selection of sand models and identification of parameters using an enhanced genetic algorithm. Int. J. Numer. Anal. Methods Geomech. 40, 1219-1240.

Jin, Y.-F., Yin, Z.-Y., Wu, Z.-X., Daouadji, A., 2018. Numerical modeling of pile penetration in silica sands considering the effect of grain breakage. Finite Elem. Anal. Des. 144, 15-29.

Jin, Z., Yin, Z.-Y., Kotronis, P., Jin, Y.-F., 2018. Numerical investigation on evolving failure of caisson foundation in sand using the combined Lagrangian-SPH method. Mar. Georesour. Geotechnol. 1-13.

Li, D., Zhang, Y., Feng, L., Gao, Y., 2015. Capacity of modified suction caissons in marine sand under static horizontal loading. Ocean. Eng. 102, 1-16.

Li, S., Liu, W.K., 2002. Meshfree and particle methods and their applications. Appl. Mech. Rev. 55 (1), 1-34.

Li, Z., Kotronis, P., Escoffier, S., 2014. Numerical study of the 3D failure envelope of a single pile in sand. Comput. Geotech. 62.

Li, Z., Kotronis, P., Escoffier, S., Tamagnini, C., 2016. A hypoplastic macroelement for single vertical piles in sand subject to three-dimensional loading conditions. Acta Geotechnica 11 (2), 373-390.

Liu, M., Yang, M., Wang, H., 2014. Bearing behavior of wide-shallow bucket foundation for offshore wind turbines in drained silty sand. Ocean. Eng. 82, 169-179.

Meyerhof, G.t., 1953. The bearing capacity of foundations under eccentric and inclined loads. Proc. of the 3rd Int. Conf. on SMFE 440-445.

Montrasio, L., Nova, R., 1997. Settlements of shallow foundations on sand: geometrical effects. Geotechnique 47 (1), 49-60.
Nguyen-Sy, L., 2005. The Theoretical Modelling of Circular Shallow Foundation for Offshore Wind Turbines. University of, Oxford.

Nguyen-Sy, L., Houlsby, G.T., 2005. The Theoretical Modelling of a Suction Caisson Foundation Using Hyperplasticity Theory. Frontiers in Offshore Geotechnics II, Perth, p. 417.

Nova, R., Montrasio, L., 1991. Settlements of shallow foundations on sand. Geotechnique 41 (2), 243-256.

Ortiz, M., Simo, J., 1986. An analysis of a new class of integration algorithms for elastoplastic constitutive relations. Int. J. Numer. Methods Eng. 23 (3), 353-366.

Salciarini, D., Tamagnini, C., 2009. A hypoplastic macroelement model for shallow foundations under monotonic and cyclic loads. Acta Geotechnica 4 (3), 163-176.

Senders, M., 2009. Suction Caissons in Sand as Tripod Foundations for Offshore Wind Turbines. University of Western Australia.

Sheng, D., Sloan, S., Yu, H., 2000. Aspects of finite element implementation of critical state models. Comput. Mech. 26 (2), 185-196.

Skau, K.S., Grimstad, G., Page, A.M., Eiksund, G.R., Jostad, H.P., 2018. A macro-element for integrated time domain analyses representing bucket foundations for offshore wind turbines. Mar. Struct. 59, 158-178.

Tjelta, T.I., 1995. Geotechnical experience from the installation of the Europipe jacket with bucket foundations. Offshore Technol. Conf. Houson, Paper. OTC 7795.

Tjelta, T.I., 2001. Suction piles: their position and application today. In: The Eleventh International Offshore and Polar Engineering Conference. International Society of Offshore and Polar Engineers. Stavangar, vol. 2, pp. 1-6.

Tran, N.X., Kim, S.-R., 2017. Evaluation of horizontal and moment bearing capacities of tripod bucket foundations in sand. Ocean. Eng. 140, 209-221.

Villalobos, F., Byrne, B., Houlsby, G., Martin, C., 2003. Bearing Capacity Tests of Scale Suction Caisson Footings on Sand: Experimental Data. Data Rep. FOT005/1. Dept. of Engineering Science, Univ. of Oxford, Oxford, UK.

Villalobos, F.A., Byrne, B.W., Houlsby, G.T., 2005. Moment loading of caissons installed in saturated sand. In: Proceedings of International Symposium on Frontiers in Geotechnics. ISFOG. University of Western, pp. 411-416.

Villalobos, F.A., Byrne, B.W., Houlsby, G.T., 2009. An experimental study of the drained capacity of suction caisson foundations under monotonic loading for offshore applications. Soils Found. 49 (3), 477-488.

Villalobos, F.A., Byrne, B.W., Houlsby, G.T., 2010. Model testing of suction caissons in clay subjected to vertical loading. Appl. Ocean Res. 32 (4), 414-424.

Villalobos, F.A., Houlsby, G.T., Byrne, B.W., 2004. Suction caisson foundations for offshore wind turbines. In: Proc. 5th Chilean Conference of Geotechnics (Congreso Chileno de Geotecnia), Santiago, pp. 24-26.

Villalobos Jara, F.A., 2006. Model Testing of Foundations for Offshore Wind Turbines. University of, Oxford.

Wu, Z.-X., Yin, Z.-Y., Jin, Y.-F., Geng, X.-Y., 2017. A straightforward procedure of parameters determination for sand: a bridge from critical state based constitutive modelling to finite element analysis. Eur. J. Environ. Civ. Eng. 1-23.

Yao, Y., Hou, W., Zhou, A., 2009. UH model: three-dimensional unified hardening model for overconsolidated clays. Geotechnique 59 (5), 451-469.

Yao, Y., Lu, D., Zhou, A., Zou, B., 2004. Generalized non-linear strength theory and transformed stress space. Sci. China Ser. E Technol. Sci. 47 (6), 691-709.

Yao, Y., Sun, D., Matsuoka, H., 2008. A unified constitutive model for both clay and sand with hardening parameter independent on stress path. Comput. Geotech. 35 (2), $210-222$.

Yin, Z.-Y., Chang, C.S., Hicher, P.-Y., 2010. Micromechanical modelling for effect of inherent anisotropy on cyclic behaviour of sand. Int. J. Solids Struct. 47 (14-15), 1933-1951.

Yin, Z.-Y., Xu, Q., Hicher, P.-Y., 2013. A simple critical state based double-yield-surface model for clay behavior under complex loading. Acta Geotechnica 8 (5), 509-523.

Yin, Z.-Y., Hicher, P.-Y., Dano, C., Jin, Y.-F., 2017. Modeling mechanical behavior of very coarse granular materials. J. Eng. Mech. 143, C4016006.

Yin, Z.-Y., Jin, Y.-F., Shen, S.-L., Huang, H.-W., 2017. An efficient optimization method for identifying parameters of soft structured clay by an enhanced genetic algorithm and elastic-viscoplastic model. Acta Geotechnica 12, 849-867.

Yin, Z.-Y., Jin, Z., Kotronis, P., Wu, Z.-X., 2018. Novel SPH SIMSAND-based approach for modeling of granular collapse. Int. J. Geomech. 18 (11), 04018156.

Yin, Z.Y., Chang, C.S., 2013. Stress-dilatancy behavior for sand under loading and unloading conditions. Int. J. Numer. Anal. Methods Geomech. 37 (8), 855-870.

Zafeirakos, A., Gerolymos, N., 2016. Bearing strength surface for bridge caisson foundations in frictional soil under combined loading. Acta Geotechnica 11 (5), $1189-1208$.

Zhang, J.H., Zhang, L.M., Lu, X.B., 2007. Centrifuge modeling of suction bucket foundations for platforms under ice-sheet-induced cyclic lateral loadings. Ocean. Eng. 34, 1069-1079.

Zhu, B., Zhang, W.-1., Ying, P.-p., Chen, Y.-m., 2014. Deflection-based bearing capacity of suction caisson foundations of offshore wind turbines. J. Geotech. Geoenviron. Eng. $140,1-12$. 